fournal of Medical Genetics (1971). 8, 1.

\title{
The 'Law of Ancestral Heredity' and the Mendelian-Ancestrian Controversy in England, 1889-1906
}

\author{
P. FROGGATT and N. C. NEVIN \\ From the Departments of Social and Preventive Medicine and Medical Statistics, and the Human Genetics Unit, \\ The Queen's University, Belfast
}

'I respect you as an honest man, and perhaps the ablest and hardest worker I have met, and I am determined not to take up a quarrel with you if I can help it. I have thought for a long time that you are probably the only Englishman I know at this moment whose first thought is to get at the truth in these [inheritance] problems .....

(Letter from William Bateson to Karl Pearson of 13 February 1902.)*

It is frequently taught that after Mendel's results were 'rediscovered' (in 1900) the 'ancestrians', $\dagger$ led by Karl Pearson, opposed their acceptance and that this retarded the development of the subject later to be called human genetics. This generalization is only partly true; and it is the purpose of this paper to examine the facts and to explain the issues involved.

There were many protagonists but we concentrate on the three who led the rival schools in England: William Bateson the 'Mendelian'; and Karl Pearson and Raphael Weldon the 'ancestrians'. (Francis Galton, whose work influenced both schools, remained largely above the battle-he was 67 in 1889-enjoying throughout the respect and confidence of all. Sir Archibald Garrod, the pioneer human geneticist and Mendelian, was not directly involved to any extent.) Such was their preeminence that restricting this article largely to their work and mutual exchanges hardly reduces the scope of the controversy or the arena of battle. We deal in most detail with the work of Pearson: of

\footnotetext{
Received, October 51970.

* Pearson, E. S. (1936). Karl Pearson: An appreciation of some aspects of his life and work. Biometrika, 28, 193-257. (Page 204, ft.-note.)

† 'Ancestrian' described the viewpoint that a phenotypic character was not independent of the expression of the same character in the ancestry, i.e. in parents, grandparents, great-grandparents, etc.
}

the three he was the most closely involved with medical and statistical opinion and could-and did-directly influence such opinion through his teaching, his writings including the publications he edited, and his personal authority in the successive posts he filled at University College, London. In addition we deal with events in a defined period of time. Any dates selected must be cut-off points on a continuum of debate; but our choice (1889-1906) is not arbitrary. The years $1889-1890$ mark a true beginning with the publication of Galton's book Natural Inheritance-which made a profound impression on all the principals-and Weldon's appointment to the Jodrell Chair of Zoology at University College, London, where he came in close contact with Pearson; while Weldon's early death in 1906 removed the most vibrant and committed of the ancestrians and the main butt for the Mendelians' attacks, and without him Pearson turned increasingly to other applications of the methods they had developed together.

This article is descriptive rather than interpretative: we describe the salient events and do not attempt any wide-ranging critical discussion of the issues raised or their impact on the development of biological thinking. To reconcile this approach with a reasonably concise and coherent narrative we have relegated some of the information to Notes which augment the customary bibliographical information. We have written for the reader acquainted with human population genetics rather than with animal or plant genetics: we have had to discuss, however, work on non-human material because Bateson and Weldon were field naturalists not human biologists, and all biological data were grist to Pearson's mill. Only Galton with his 
anthropometric interest and his habit of collecting data from the general public, and to a lesser extent Pearson, dealt with human measurements and traits to any extent.

Finally, many of the exchanges were acrimonious, some even grossly offensive, and read oddly today. Apologists argue that with the issues and personalities involved a vigorous and emotive style was inevitable and even necessary and that the exchanges did not transgress the accepted canons of contemporary expression and polemic. We pass no judgement on this view.

\section{PART I: 1889-1900}

\section{Development of the Ancestrians' Interest}

In June 1884, Pearson succeeded Olaus Henrici as Goldsmid Professor of Applied Mathematics and Mechanics at University College, London. He was only 27. Two previous applications for chairsthat of Mathematics at Queen's College, Manchester, in 1881, and that of Pure Mathematics at University College, London, in 1883-had been unsuccessful. After he had come down from King's, where he was

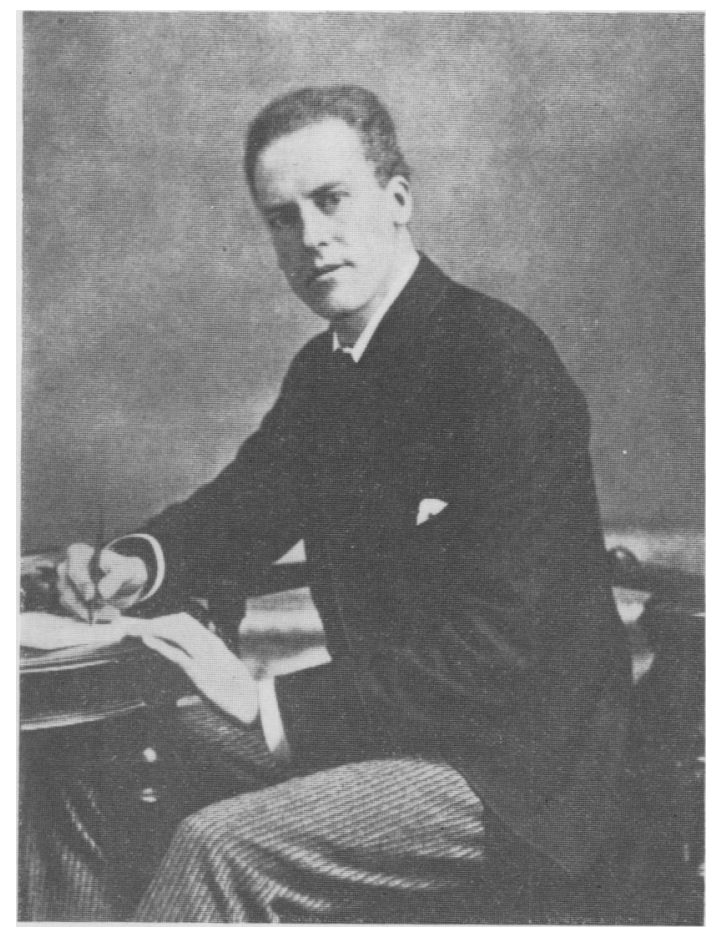

FIG. 1. Karl Pearson in 1890 aged 32. (Reproduced by courtesy of The Cambridge University Press and Professor E. S. Pearson on behalf of the Biometrika Trustees from Pearson, E. S. (1938). Karl Pearson: An Appreciation of Aspects of his Life and Work, Plate III. The University Press, Cambridge.)
Third Wrangler in the Tripos in 1879, Pearson had written on a catholic range of subjects ${ }^{1}$ encompassing history, ethics, philosophy, art, mathematics, and political thought ${ }^{2}$ but at the time of his appointment he had published only five original contributions in mathmatics and science, ${ }^{3}$ and these were in strictly physical fields. During the rest of the eighties the development of this work, ${ }^{4}$ the completion of Clifford's The Common Sense of the Exact Sciences, ${ }^{5}$ his monumental editing of Todhunter's History ${ }^{6}$ (much of the first volume ${ }^{4}$ and most of the 1300 pages of the second were written by Pearson himself),${ }^{7}$ his heavy teaching load and wide outside interests, ${ }^{8}$ absorbed Pearson's energy and time; but now there was developing that passion for seeking knowledge and truth by thinking freed from dogma which was detectable in his earlier works ${ }^{9,10}$ and which was to be so forcibly expressed in his contemporary books The Ethic of Freethought ${ }^{11}$ and The Grammar of Science ${ }^{12}$ and consistently manifest throughout his writings.

Though Pearson was at this time familiar with general concepts of heredity and evolution he had not developed any specific interest in them. ${ }^{13}$ All this was changed by two events: the publication, in 1889, of Galton's Natural Inheritance $;^{14}$ and the appointment, in 1890, of Raphael Weldon to succeed Ray Lankester in the Jodrell Chair of Zoology at University College, London. These were to have decisive and in a way complementary influences in shaping Pearson's scientific work and in leading him into the then unborn subject of biometry.

Natural Inheritance was a landmark and had a profound effect on the development of human biology. It created Galton's school and 'induced Weldon, Edgeworth, and myself [Pearson] to study correlation and in doing so to see its immense importance for many fields of enquiry' ${ }^{15}$ specifically, it led Pearson to statistics especially as applied to biological processes and phenomena. Pearson was critical of some of Galton's methods ${ }^{16}$ but he saw clearly the epoch-making nature of the work and was fired with enthusiasm by it. Forty-five years later he recalled his feelings:

'In 1889 [Galton] published his Natural Inheritance. In the Introduction to that book he writes: "This part of the enquiry may be said to run along a road on a high level, that affords wide views in unexpected directions, and from which easy descents may be made to totally different goals to those we have now in reach." "Road on a high level", "wide views in unexpected directions", "easy descents to totally different goals",- -here was a field for an adventurous roamer!... I interpreted that sentence of Galton to mean that there was a category 


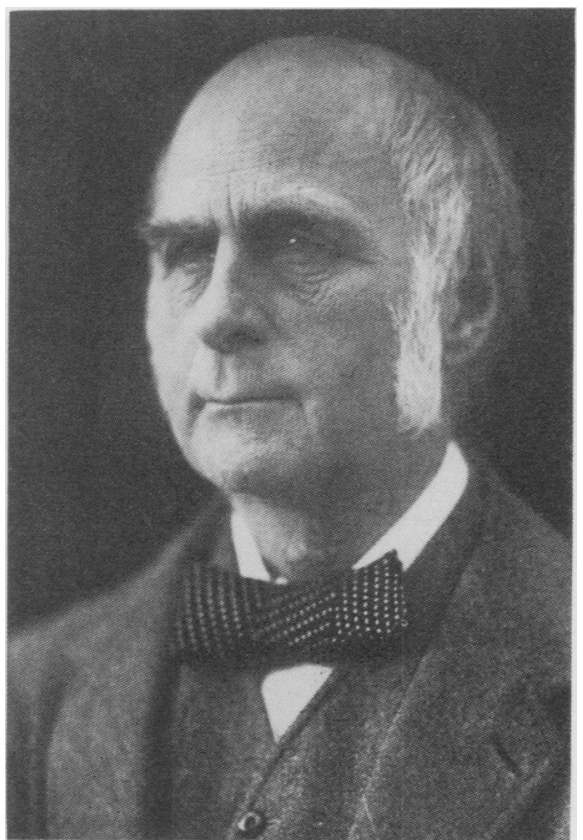

FIG. 2. Francis Galton in 1902 aged 80. (Reproduced by courtesy of The Cambridge University Press and Professor E. S. Pearson on behalf of the Biometrika Trustees from Pearson, K. (1930). The Life, Letters and Labours of Francis Galton, Vol. IIIA, Plate XXXI. The University Press, Cambridge.)

broader than causation, namely correlation, of which causation was only the limit, and that this new conception of correlation brought psychology, anthropology, medicine and sociology in large parts into the field of mathematical treatment. It was Galton who first freed me from the prejudice that sound mathematics could only be applied to natural phenomena under the category of causation. Here for the first time was a possibility, I will not say a certainty, of reaching knowledgeas valid as physical knowledge was then thought to bein the field of living forms and above all in the field of human conduct.'17

Exciting as these revelations were they alone would not necessarily have led Pearson to the study of inheritance; he could as easily have entered other 'fields of living forms and human conduct'. It was Weldon's enthusiasm and vigour, his eagerness to have Darwinian evolution demonstrated by statistical inquiry (Darwin's theories were hypothetical and had never been put to test), and (from 1891) his daily contact with Pearson, which tipped the scales. As Pearson himself wrote: 'Both [Weldon and Pearson] were drawn independently by Galton's Natural Inheritance . . . but of this the writer feels sure, that his earliest contributions to biometry were the direct result of Weldon's suggestions and would never have been carried out without his inspiration and enthusiasm.'18

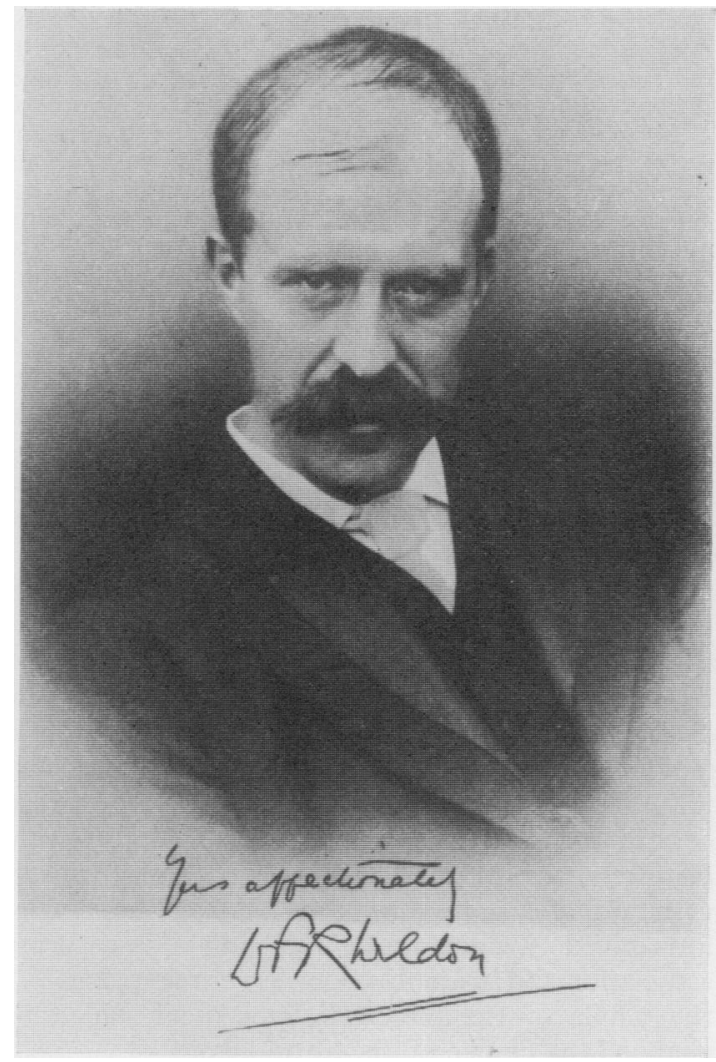

FIg. 3. Raphael Weldon. (Reproduced by courtesy of The Cambridge University Press and Professor E. S. Pearson on behalf of the Biometrika Trustees from Pearson, K. (1906). Walter Frank Raphael Weldon, 1860-1906. Biometrika, 5, 1-52.)

Walter Frank Raphael Weldon, Pearson's associate and close friend, was born in Highgate in 1860 to Walter Weldon and Anne (née Cotton). His father (d. 1885) had been a journalist before making discoveries in industrial chemistry which led to a fortune and his election as F.R.S. ${ }^{19}$ his mother, a stern disciplinarian, strongly influenced his early life and character. One sister died in 1861 aged 6, and his younger brother Dante died of 'apoplexy' in 1881 during his first year at Peterhouse, to be followed within a few weeks by his mother. These sudden bereavements and the comparatively early deaths of his parents acted on his deeply emotional nature and, by seeding the doubt whether he would live to finish his work, generated some of his remorseless drive and restless energy.

After private tutoring and boarding-school at Caversham, Weldon entered University College, London, in 1876, where among other subjects he studied mathematics (under Henrici) and zoology (under Lankester). The next year he transferred to King's College, Cambridge, with a view to entering medicine, but in 1878 he enrolled at St. John's and despite a period of illness from overwork, took a first in the Natural Science Tripos in 1881. He was appointed demonstrator and, on election in 1884 as a fellow of St. John's, lecturer in invertebrate morphology. In 1891 he went to 
University College, London, as Jodrell Professor of Zoology but moved to Oxford in 1900 on appointment to the Linacre Chair. He died from pneumonia on Good Friday, 1906, aged only 46 . In 1883 he married Florence Tebb who was his constant companion on his frequent travels and who helped with many laborious calculations and breeding experiments. There were no children. Weldon was elected F.R.S. in 1890 and was honoured by many scientific societies. His work was closely linked to that of Pearson and together as 'Galton's lieutenants' they mainly fashioned the biometric school. ${ }^{20}$

During the eighties while Pearson laboured at applied mathematics in London, Weldon embarked on his life work: testing Darwinian views of evolution. He divided his time between teaching at Cambridge, field work in Europe, the Channel Islands, and the Caribbean, and (from 1888) experimentation at the Marine Biological Laboratory in Plymouth. His early papers show an orthodox approach towards elucidating Darwinian principles by strict morphological studies, but later in the decade he came to realize the limitations of these methods-especially in that they largely neglected 'differences between individual members of a race or species'21 - and increasingly 'his thoughts were distinctly turning from morphology to problems in variation and correlation'. ${ }^{22}$ Natural Inheritance introduced Weldon to a method of measuring association and 'from this book as source springs ... the whole of the biometric movement which so changed the course of his life and work'. ${ }^{23}$

Weldon saw immediately the importance of Galton's work on frequency distributions and correlation to the study of evolution-frequency of deviations from the type could now be described and organic associations measured-and he at once set to use these tools to fashion answers to those problems which seemed insoluble from morphological or embryological inquiry. In Plymouth he started his monumental series of measurements on the common shrimp (Crangon vulgaris) which were to confirm the findings Galton had at first anticipated, ${ }^{24}$ then developed, ${ }^{25-27}$ and finally more fully stated ${ }^{14}$ for man, viz. that many organic measurements are normally distributed ${ }^{28}$ and (in a second paper) that the 'degree of correlation' between two organs is approximately the same for each local race of the species and the regressions are linear. ${ }^{29}$ The first paper was refereed favourably by Galton ${ }^{30}$ with whom Weldon also corresponded on the second before its publication. ${ }^{31}$ At this time Weldon did not know Pearson; ${ }^{32}$ they first met when Weldon took up the Jodrell Chair early in 1891.

On 18 November 1890, before Weldon's arrival at University College, Pearson applied for the Gresham
Professorship in Geometry ${ }^{33}$ and was appointed on 3 March $1891,{ }^{34}$ and the growing influence on his thinking of Weldon and Galton can be judged from the Gresham syllabuses. ${ }^{35,36}$ His first (March and April 1891) and second (November 1891 to May 1892) lecture courses dealt little with biological problems; in the third (November 1892 to May 1893) the application of probability theory was developed; while by the fourth and last ${ }^{37}$ series (November 1893 to May 1894) he had turned strongly to the consideration of methods required for the solution of evolutionary problems. ${ }^{38}$

Pearson's first practical involvement was in late 1892, and was due entirely to Weldon. In the summer of 1891 the Weldons studied the Plymouth Sound shore crab (Carcinus moenas), and at Easter 1892 the Naples race of the same species. Eleven parameters of the carapace (shell) in 2000 crabs were measured and in only one instance (frontal breadth in the Naples race) was the distribution skew. ${ }^{39}$ This curve was bimodal-'double humped' was Weldon's term-and Weldon was able to show that it could be a composite of two normal distributions. He was exhuberant at this evidence of dimorphism in what was catalogued as a single 'type', and in a letter to Galton concluded 'either Naples is the meeting point of two distinct races of crabs, or a "sport" is in process of establishment. You have so often spoken of this kind of curve as certain to occur that I am glad to send you the first case which I have found.' ${ }^{40}$ The same day he wrote to Pearson: 'In the last few evenings I have wrestled with a double humped curve, and have overthrown it. Enclosed is the diagram and [numerical results].... If you scoff at this I shall never forgive you. ${ }^{\prime 1}$ Pearson did not scoff: instead he rose to the challenge. He confirmed the validity of Weldon's inference of two normal populations compounding the 'double humped' curve, recalculated the statistics for Weldon's paper, ${ }^{39}$ and dealt for the first time with the dissection of a distribution assumed to be a composite of two or more normal distributions. ${ }^{42}$ This paper was the first of Pearson's great series 'Mathematical contributions to the theory of evolution', ${ }^{43}$ and heralded the development of that rigorous analytical approach which was to characterize the biometric school and allow them to challenge accepted principles and tenets. Weldon expressed this view exactly: 'It cannot be too strongly urged that the problem of animal evolution is essentially a statistical problem. ... These [problems] are all questions of arithmetic; and when we know the numerical answers to these questions for a number of species we shall know the direction and the rate of change in these species at 
the present day-a knowledge which is the only legitimate basis for speculations as to their past history and future fate. ${ }^{39}$

This year-1893-marked a major turning point in Pearson's career: he had ideas and he intended to work them out in practice. This required more than Weldon's mere 'arithmetic': it required an advanced theory of statistics and this Pearson founded in several series of papers over the next decade. His purpose was to develop statistical tools for studying, mainly though not exclusively, problems of evolution and heredity: and we can attribute to this pioneering his frequent concern more with the technical aspects of the solutions he derived and their valid application than with the interpretation and theoretical possibilities of the results which flowed from them, or indeed even with the quality of the source data and the fundamentals of the phenomena which generated themhis main, even if relative, failings.

Two immediate objectives stand out: (i) the testing of the adequacy of Galton's 'law of ancestral heredity ${ }^{\prime 4}$ - which led to a more accurate statement of its assumptions; and (ii) the development of methods by which to measure variability and correlation and the influence on these of various types of selection, and to use these on data from populations under natural conditions rather than from experiments on individuals or species. Both of these struck at the heart of the evolutionary debate, viz. how in general do animals vary and what causes and maintains this variation, and in what way, under what 'laws', and by what mechanisms are characters inherited? The steps taken up to 1900 towards achieving these two objectives will now be described.

\section{The Law of Ancestral Heredity}

Development by Galton. During the late eighteen-fifties Galton's interests turned increasingly from the study of man's environment (he was a well-known explorer and geographer) to the study of man himself: 'About the time of the appearance of Darwin's Origin of Species [1859] I had begun to interest myself in the Human side of Geography and was in a way prepared to appreciate his view. ${ }^{45}$ Late in $1864^{46}$ he wrote two papers entitled 'Heredity talent and character', ${ }^{47}$ in which he claimed that a wide range of 'mental aptitudes' and components of 'general intellectual power' could be inherited just as could physical characteristics. In the second paper he stated: 'The share a man retains in the constitution of his remote descendants is inconceivably small. The father transmits, on an average, one-half of his nature, the grandfather one-fourth, the great-grandfather one-eighth; the share decreasing step-by-step in a geometrical ratio with great rapidity.' Despite its misstatementGalton refers, by an 'obvious oversight', ${ }^{48}$ to 'father', 'grandfather' etc., instead of to 'midparent', 'mid-grandparent', etc.-these views on ancestral contributions represent the first, though primitive, enunciation of the 'law of ancestral heredity'-termed below 'the ancestral law'.

At this time Galton adduced no worthwhile data for the law's validity; his articles contained simply lists of distinguished men who had also able relatives. On what evidence then did he shape his ideas? There is no unequivocal answer. Undoubtedly his postulation of the geometric series $\frac{1}{2}, \frac{1}{4}, \frac{1}{8}$... could have been reached from mathematical development of Darwin's 'provisional hypothesis of pangenesis'49 (the series would run $\mathbf{r}+\frac{1}{2} \mathbf{r}+\frac{1}{4} \mathbf{r} \ldots$, with $\mathbf{r}=\frac{1}{2}$ and accepting-contrary to the theory-that the individual whose characteristics were being predicted showed no 'unexplained' variation of his own): but his papers were drafted four years before the promulgation of Darwin's pangenesis theory ${ }^{46}$ and at least six months before Darwin's preparation of the relevant MS. ${ }^{50}$ This suggests that Galton reached his theory independently: ${ }^{51}$ if so it can be speculated that he did so as a simple corollary of 'blending inheritance' (i.e. the hereditary mixing of paternal and maternal elements so that characters in the offspring would be mid-way between those in the parents) which had then been accepted as axiomatic for organic nature since the eighteenth century. ${ }^{52}$ In any event the guarded enthusiasm with which he first welcomed pangenesis, ${ }^{53}$ and which owed more to his esteem for Darwin than to the merits of the theory, was short-lived, yet his belief in the wide applicability of the ancestral law remained undiminished for the rest of his life. ${ }^{54}$ A few years after his initial papers ${ }^{47}$ Galton was to promulgate his physiological theory of inheritance based on his concept of 'stirp' (stirpes $=\mathrm{a}$ root), and this offered a theoretical basis for the ancestral law by validating the choice, for the partitioning of the 'ancestral heritage', of a geometric series which must sum to unity. ${ }^{55}$ It seems at least possible that ideas which were to lead to 'stirp' as a physiological explanation for the phenomenon of 'blending' were germinating in his mind as early as the 1865 papers. ${ }^{47}$

The physiological theory of 'stirp' and his empirical acceptance of ancestral contribution to the phenotype led Galton to propound his 'law': what was now needed were data and techniques for their analysis, particularly a method for measuring degrees of resemblance in quantitative characteristics. He developed for this purpose regression, then 
correlation theory, and applied the principles first to size of parental and offspring sweet-pea seed, ${ }^{56}$ then, after a period of eight years of doubts as to the underlying assumptions, to such data from man as stature ${ }^{57}$ eye-colour, ${ }^{58}$ disease, the 'artistic faculty', good and bad temper, and others, most collected from his 'Anthropometric Laboratory', 59 'Record of Family Faculties' (R.F.F.), ${ }^{60}$ and 'Life History Album' ${ }^{1}$ and many of which he brought together in Natural Inheritance. ${ }^{14}$ The ancestral law is set out fully, though tentatively, for the first time in $1885 ; 25$ the results are summarized, the law reformulated 'with hesitation', and a proof adduced in $1889 ;^{14}$ and, as 'a statistical law of heredity that appears to be universally applicable to bisexual descent', confidently presented in $1897 .{ }^{62}$ The validity of the assumptions has been studied in detail by Pearson ${ }^{3}$ - though his treatment is very difficult to follow-and recently summarized by Swinburne $;^{51}$ we give only a resumé here.

Galton's data on stature showed the mean height of offspring to be closer to the generation mean than was the mean parental height to its generation mean: in his expressive language the (average) offspring was 'more mediocre' or 'less exceptional' than the (average) mid-parent. ${ }^{63} \mathrm{He}$ estimated this 'filial regression' as $\frac{2}{3}$-'that is to say ... the proportion in which the Son is, on average, less exceptional [as regards height] than his Mid-Parent ${ }^{\prime 64}$-and calculated other regression coefficients of $\frac{1}{3}$ for midparent on offspring and for offspring on one parent, $\frac{2}{3}$ for brother on brother, ${ }^{65}$ and, by multiplying appropriate coefficients, reached 'implied' (but invalid) ${ }^{66}$ values for the relationships between more distant kin.

Galton then tried to deduce the separate contributions of each ancestor to the deviation from the mean of the offspring's phenotype. ${ }^{67}$ By dubious mathematics he reached an initial solution that the 'total bequeathable property' to an individual is

$$
\mathrm{D}\left(1+\frac{1}{3}+\frac{1}{9}+\cdots\right)=\frac{3 \mathrm{D}}{2},
$$

where D is the 'peculiarity' (deviation from the population mean) of the mid-parent and, as initially expressed, ${ }^{25,26}$ the expansion represents 'the sum of the deviates of all the mid-generations that contribute to the heritage of the offspring'. He then considered whether this 'bequeathable property' diminishes in passage through generations, a problem germane to his physiological concept of 'stirp'. He examined two extreme cases: (a) where there is no diminution-in his nomenclature 'the bequests by the various generations [are] equally taxed', 68 and (b) where it wanes geometrically through each generation; and he reached, by grossly invalid $\mathbb{\Phi}$ methods, ${ }^{51,66}$ values for the diminution at each $\underset{\oplus}{\vec{P}}$ generation of $\frac{4}{9}$ on assumptions under (a) and $\frac{6}{11}$ on those under (b). He concluded: 'These values $\stackrel{\vec{S}}{\rightarrow}$ differ but slightly from $\frac{1}{2}$, and their mean is closely믈 $\frac{1}{2}$, so we may fairly accept that result $\left[\frac{1}{2}\right] .^{, 26,68}$ Then, 흘 without comment he blandly chose the geometrical $\frac{\bar{c}}{7}$ case (b) and concluded: 'Hence the influence, pure $\stackrel{\mathbb{Q}}{\square}$ and simple, of the mid-parent may be taken as $\frac{1}{2}$, of the mid-grandparent $\frac{1}{4}$, of the mid-greatgrand- $\frac{}{1}$ parent $\frac{1}{8}$, and so on. That of the individual parent would therefore be $\frac{1}{4}$, of the individual grandparent $\frac{1}{16}$, of an individual in the next generation $\frac{1}{64}$, and so on'26 (Fig. 5, see p. 13). He had finally reached the answer he had first guessed, then theorized must be true, twenty years before! We shall see later that his preference for the geometric series was wise even if $\overrightarrow{ }$ 'it was inspiration rather than correct reasoning which led him to it', ${ }^{69}$ and that by its choice he gave a starting point for Pearson to develop the theory of multiple regression.

Galton then turned from the 'blended' characteristic-stature-to consider the applicability of the ancestral law to traits considered to be transmitted under 'alternative' inheritance, in the first instance to eye-colour. ${ }^{70} \mathrm{He}$ amended the original assumptions and now hypothesized that the ancestry would contribute the postulated proportions not of the character, e.g. stature in the (average) individual descendant, but of the character, viz. eye-colour, in the pooled offspring of each generation, i.e. a parent's eye-colour would completely determine on average that of $\frac{1}{4}$ of his or her offspring, that of a grandparent $\frac{1}{16}$, etc.-'reversion' rather than 'regression'. He wrote: 'But if one parent has a light eye-colour and the other a dark eye-colour, the children will be partly light and partly dark, and not medium.... The blending of stature is due to its being the aggregate of the quasi-independent inheritances of many separate parts while eye-colour appears to be much less various in its origin." 58 Using the R.F.F. data and ingenious methods for 'rateably assigning' intermediate tints, Galton reached expected ratios of dark- and light-eyed types to compare with those observed. Concordance was good-in Pearson's view 'remarkable ... considering the contradictory assumptions on which they [the expected ratios] are based ${ }^{71}$-and Galton concluded: '. . . we may with some confidence expect that the law by which these hereditary contributions are governed will be widely and perhaps universally applicable'. ${ }^{58}$

Confirmed now in his faith in the ancestral law for both qualitative and scalar characters Galton turned to examine its universality. After abortive efforts 
to obtain (with F. Merrifield) data from breeding the Purple Thorn moth (Silenia illustraria) ${ }^{72}$ and 'taking some steps' to experiment with mice, ${ }^{73}$ he used the coat-colour of Sir Everett Millais' pedigree stock of Basset Hounds. ${ }^{62,74}$ There were only two phenotypes-'tricolour' and 'non-tricolour'-and classification was known often for four complete generations. Accepting now the law as applicable, i.e. the validity of the regression coefficients, Galton again obtained close agreement of expected with observed ratios and took this as indicative of the universality of the law, at least in the animal kingdom. Pearson was hardly less enthusiastic. ${ }^{75}$ Not all, however, echoed these two, particularly hybridists, but Galton was quick to point out that the ancestral law applied only to 'offspring of parents of the same variety ... in short it has nothing to do with hybridism'. ${ }^{76}$ This distinction was important and the ancestrians made much of it after 1900: Mendel's original paper after all was entitled 'Experiments in Plant Hybridisation'.

Between 1897 and 1900 Galton wrote several short papers germane to the ancestral law $;^{76-78}$ but the centre of the stage was now to be surrendered to Pearson who, in his treatment of Galton's ideas, was to develop multiple regression theory and introduce enormous mathematical complications into the primitive hypotheses.

Modification by Pearson. Some ambiguities exist in Galton's writings as to whether he was setting out exclusively a law of phenotypic resemblance or one establishing a physiological hypothesis of inheritance. ${ }^{51}$ Probably he was doing both. There was no doubt, however, in Pearson's mind as to his own interpretation. Unlike Galton he had no preconceived ideas about inheritance; to him Galton's law was 'not a biological hypothesis, but the mathematical expression of statistical variates ... [which] can be applied ... to many biological hypotheses' $;^{79}$ and he now set out to put the theory on a more rigorous footing and to establish the modifications necessary under conditions crucial to various forms of 'selection'. He recognized the imperfections in Galton's derivation, but he was unconcerned: his philosophy convinced him that all phenomena could be brought under statistically expressed laws and he was certain that Galton's geometric assumption was correct even though the regression constants $\left(\frac{1}{2}, \frac{1}{4} \cdots\right)$ may not stand test. $\mathrm{He}$ would fashion the absolute answers from Galton's crude blueprint.

Pearson's direct involvement dates from $1896,{ }^{80}$ the year before Galton's definitive enunciation of his ancestral law. ${ }^{62}$ In this paper, ${ }^{80}$ the third in the series 'Mathematical contributions to the theory of evolution', Pearson gave inter alia the theory of higher-order correlation ${ }^{81}$-introducing the expression 'coefficient of double correlation' ('partial' and 'multiple' correlation were first developed by Yule); ${ }^{82,83}$ evaluated, on Galton's R.F.F. data, partial regressions of offspring on each parent; and considerably extended his collateral studies of heredity (see below) by considering types of selection, assortative mating, and 'panmixia'. $\mathrm{He}$ also misinterpreted Galton in a way ${ }^{84}$ that led him to the paradoxical conclusion that 'a knowledge of the ancestry beyond the parents in no way alters our judgement as to the size of the organ or degree of characteristic probable in the offspring' ${ }^{85}$

After a further, preliminary article, ${ }^{86}$ Pearson considered the ancestral law in a basic paper ${ }^{87}$ subheaded 'A New Year's greeting to Francis Galton, January 1, 1898'. ${ }^{88}$ In this Pearson propounded what he now christened 'Galton's Law of Ancestral Heredity', in the form of the multiple regression equation of offspring on 'mid-parental' ancestry

$$
\mathrm{x}_{0}=\frac{1}{2}\left(\frac{\sigma_{0}}{\sigma_{1}} \mathrm{x}_{1}\right)+\frac{1}{4}\left(\frac{\sigma_{0}}{\sigma_{2}} \mathrm{x}_{2}\right)+\frac{1}{8}\left(\frac{\sigma_{0}}{\sigma_{3}} \mathrm{x}_{3}\right) \ldots,
$$

where $x_{0}$ is the predicted deviation of an offspring from the generation mean, $x_{1}$ is a linear function of the deviation of the 'mid-parent' from that generation mean, $\mathbf{x}_{2}$ similarly for the 'mid-grandparent', and so on, and $\sigma_{0}, \sigma_{1} \ldots$ the standard deviations of the appropriate generations of the offspring, and from this deduced theoretical values for various regression and correlation coefficients between kin. $\mathrm{He}$ also generalized the geometric series of partial regression coefficients thus raising the parental correlations, tested observation (from Galton's stature data) against these expectations, evaluated fraternal correlations, and examined the effect on the constants of 'ancestral taxation' and of changes in offspring variability through generations. He sweepingly concluded: 'If Darwinian evolution be natural selection combined with heredity, then the [ancestral law] must prove almost as epoch-making to the biologist as the law of gravitation to the astronomer'; and again: 'If either that [Galton's] law, or its suggested modification be substantially correct, they embrace the whole theory of heredity. They bring into one simple statement an immense range of facts, thus fulfilling the fundamental purpose of a great law of nature. ${ }^{87}$ Here was the demonstration of the truth of his rationalist philosophy-that there existed great universal natural laws which could be expressed mathematically and which could ultimately be brought into a single system. He had written earlier: 'Many of our so-called laws are 
merely empirical laws, the result of observation; but the progress of knowledge seems to me to point to a far distant time where all finite things of the universe shall be shown to be united by law, and that law itself to be the only possible law which thought can conceive. ${ }^{\prime 89}$ Small wonder he was later disinclined to abandon belief in these 'ancestrian principles'.

Pearson saw clearly the line of inquiry he must now follow. He knew that the ancestral formula would need revision when selection, assortative mating, and differential fertility were taken into account, and he clearly signalled his intention to investigate such effects further. ${ }^{90}$ Thus the road ahead joined those from his other work on inheritance (see below) to form a common highway along which he was travelling in 1900 . Before this, however, there was one outstanding problem to be tackled. Pearson had also been critical of Galton's handling of qualitative traits $^{58,62}$ and he now settled to devise more appropriate methods. ${ }^{91}$ This led him at first to the fourfold table and 'tetrachoric $r^{\prime 92}$ which he used to measure kinship resemblance on assumptions of alternative ('exclusive') inheritance, ${ }^{91}$ and then to a more general treatment of 'reversion', i.e. the phenomenon where, for the character in question, the offspring resembles completely one or other parent or 'reverts' to a more distant ancestor, but no intermediate types occur. ${ }^{93} \mathrm{He}$ was able to restate, for such traits, Galton's crude law in the form of a 'law of reversion', which he carefully distinguished from the true ancestral law.

'In both cases [blended and alternative inheritance] ${ }^{94}$ we may speak of a law of ancestral heredity, but the first predicts the probable character of the individual produced by a given ancestry, while the second tells us the percentages of the total offspring which, on the average, revert to each ancestral type. I ... term the first the law of ancestral heredity, it applies to blended inheritance; the second I term the law of reversion, it applies to exclusive inheritance. ... In the former case every ancestor contributes, it may be a very small share of his character to each offspring; in the latter case each ancestor contributes the full intensity of his character to his share, and it may be an indefinitely small share, of the offspring. These two conceptions, summed up in the terms regression and reversion, ought to be kept apart.'95

Both these 'laws', despite heavy qualifications, ${ }^{96}$ assume some mechanism of (geometrically waning) ancestral dilution; in fact the seeming antithesis of Mendelism as first presented. Pearson, though not Galton or Weldon, was not unduly concerned as to what this mechanism might be: first establish the statistical relationships and then see what physiological hypothesis of inheritance accords with them best. He concluded:
'Till we know what class of characters blend, and what class of characters is mutually exclusive, we have not within our cognizance the veriest outlines of the phenomena which the inventors of plasmic mechanisms are in much haste to account for. ... The numerical laws for the intensity of inheritance must first be discovered from wide observation before plasmic mechanics can be anything but the purest hypothetical speculation.,97

These words were written in $1899 .{ }^{98}$ On the eve of the 'rediscovery' they show that Pearson, and in fact also Weldon, were not wedded to any particular biological theory of inheritance. This should be borne in mind when considering the basis of the Mendelian-ancestrian controversies which were shortly to erupt.

\section{Selection and Variability}

Weldon and the Evolution Committee of the Royal Society. We have seen that Pearson was first drawn to problems in evolution by analysing Weldon's 'double humped' curve ${ }^{42}$ and that Weldon had grasped immediately the importance of being able to demonstrate intraspecies sub-types as a preliminary to identifying factors in selection. ${ }^{39}$ Only three weeks after these papers were presented at the Royal Society (16 November 1893), Weldon characteristically took the initiative in trying to broaden the experimental scope: he arranged a meeting with Galton and R. Meldola to discuss possible Royal Society sponsorship for a joint project into heredity. ${ }^{99}$ They petitioned the Royal Society to establish a committee 'for the purpose of conducting statistical inquiries into the variability or organisms', ${ }^{100}$ and this committee-'The Committee for Conducting Statistical Enquiries into the Measurable Characteristics of Plants and Animals'was constituted on 18 January 1894 with Galton as chairman, Weldon as secretary, and a grant of $£ 50$. It held its first meeting on 25 January. ${ }^{101}$

Weldon had already started work on selective death-rates in Plymouth Sound shore crabs: testing orthodox Darwinian selection but by non-Darwinian methods. Apart from measurements on herring and the ox-eyed daisy-which were never published ${ }^{102}$ - these crab results were the first undertaken for the committee and comprised its first two Reports. ${ }^{103,104}$ These Reports are important in several ways: they formulated 'the whole range of problems which must be dealt with biometrically before the principle of selection can be raised from hypothesis to law' ${ }^{105}$ they raised what was the then novel idea that Darwinian theory was amenable to statistical testing; they were the font from which sprang most of the work on the influence of selection on variability and, its corollary, the influence of 
selection during growth; and they stimulated Pearson: 'I realise also how much of my own work flowed directly from the suggestiveness of this paper [the first Report].'106

These papers were generally unfavourably received by biologists, particularly by William Bateson who was to prove the most influential and outspoken critic of the biometric school and the ancestrian ideas. Weldon had suggested that (a) 'sports' (recognizable mutations) only contributed to evolution in exceptional circumstances, selection acting on continuous variation being the more likely source of specific modification, and (b) evolution and selection were mass phenomena to be studied by appropriate statistical methods. ${ }^{104}$ (a) Represented more or less orthodox (and accepted) Darwin-Wallace views though they were anathema to those who, like Bateson, held that any advantage (or disadvantage) accompanying slight variations must be themselves slight and relatively unimportant in evolution compared to the much less frequent but more variant 'sport'. However (b), if not a revolutionary concept, introduced into the evolutionary debate a methodology with which very few biologists were familiar and for which many felt actual repugnance. One has only to read Weldon's Report $^{103}$ with its substantial mathematics and statistics to realize this: even today's numerically trained biologist would find parts he little understood. Many biologists accordingly used some imperfections in Weldon's arguments and treatment to discredit his ill-understood approach, and if they were followers of Bateson they also used them to discredit Weldon's ideas. A gulf now opened between on the one hand the 'biologist' ${ }^{107}$ and on the other the 'biometrician' and 'ancestrian', and this was soon to be deepened by the personal animosity which, already seeded, rapidly developed between Weldon and Bateson-formerly close friends, now increasingly bitter enemies. ${ }^{108}$ The course of these controversies and enmities are examined later but it is convenient to record here that in the previous year (1894) Weldon had annoyed Bateson by adversely reviewing ${ }^{109}$ the critical, though not the descriptive content, of Bateson's great book Materials for the Study of Variation ${ }^{110}$ (in which the author advocated the more or less exclusive importance to evolution of discontinuity and variant forms) and with others ${ }^{11-114}$ had attacked Bateson's views $^{115,116}$ on the origin of the cultivated Cineraria. ${ }^{117}$

Galton was now placed in a difficult position. The 'folios' of written criticism of Weldon's Reports, 'purely controversial ... [and] some even eighteen sheets long', ${ }^{118}$ were addressed to him as chairman of committee. They were not solely 'controversial', they were also highly disparaging of the committee for endorsing the work and carried an implied criticism of Galton himself. ${ }^{119}$ Most, though not all, ${ }^{120}$ were written by Bateson and these alone 'occupied an entire box in Weldon's papers' ${ }^{121}$ Galton had always respected Weldon and felt intuitively compelled to protect him against Bateson for whom he had little personal sympathy. Intellectually, however, he was uncommitted as to one or the other: though he agreed with many of Weldon's ideas he did not care for the minor role in which Weldon cast 'sports' in the evolutionary process; ${ }^{122}$ and he had welcomed Bateson's book ${ }^{110}$ for 'bearing the happy phrase in its title of "discontinuous variation"... it does not seem to me by any means so certain as is commonly supposed by the scientific men at the present time [1894] that our evolution from a brute ancestry was through a series of severally imperceptible advances' ${ }^{123}$ He therefore fairly sought conciliation-first, by appointing (in 1896) Pearson to the committee to add an authoritative statistical voice, ${ }^{124}$ and second, by persuading Weldon to agree to Bateson himself becoming a member. ${ }^{125}$ This also furthered his own longerterm objective-to co-ordinate, then integrate, all work on evolution (horticultural, zoological, and human) through a widely-based committee, and this committee must in practice include Weldon, Pearson, and Bateson. ${ }^{126}$ Consequently, in January 1897, nine 'zoologists and breeders', including Bateson, 127 'some of whom had small desire to assist quantitative methods of research', ${ }^{128}$ were elected, and later that year the committee was reconstituted as the 'Evolution (Plants and Animals) Committee'. ${ }^{129}$ Such development was probably inevitable given the committee's need to encompass disparate views; but the decision was coldly received by Pearson and Weldon nonetheless. Harmony and the biometricians' dominance were sacrificed: 'the old statistical object is dropped ... and the whole scheme of breeding and enquiry by circulars to breeders, comes into being' ${ }^{130}$ Pearson promptly ceased to attend and later resigned ${ }^{131}$ along with Weldon and others on 25 January 1900. Mostly out of duty Galton stayed on until later in the year. After this 'capture' the committee, under F. D. Godman, became very largely a vehicle for the work and views of Bateson and was stigmatized by Pearson as 'merely a body for running Mendelism'. ${ }^{132}$

While Galton was struggling to reconcile the irreconcilable, Weldon continued his work on crabs; but his Report was never published. ${ }^{133}$ Then a new forum presented. In 1898 he became President of the Zoological Section of the British Association, 
and in his Address $^{134}$ considered the question of measurable natural selection. He showed that compared to crabs with larger frontal breadth relaative to shell length, those with smaller breadth survived longer in polluted Plymouth Sound water, though not in fresh water, and he ascribed this to their more efficient water filtration through the gillchambers. ${ }^{135}$ This delighted him since it seemingly demonstrated a basic Darwinian hypothesis, viz. specific modification by a gradual process resulting from the 'accumulation of innumerable slight variations, each good for the original possessor'. ${ }^{136}$ $\mathrm{He}$ was disappointed that it attracted only moderate support: the idea was too prevalent that Darwinian theory was incapable of statistical testing and to suggest otherwise excited suspicion and even hostility.

In February 1899 Weldon moved to Oxford: from then apart from correspondence ${ }^{137}$ his contact with Pearson was to be mainly through their joint editorship of Biometrika and their mutual working holidays, often with Galton, ${ }^{138}$ which were to produce and nurture many ideas, three papers ${ }^{139-141}$ and at least one joint review. ${ }^{142}$ Their lives continued to the end in perfect harmony ${ }^{143}$ and their championing of the biometric method united and in style complementary- Weldon with his dashing cavalry charges into the foe, Pearson with his heavier artillery'. ${ }^{144}$ Such understanding and solidarity were to be important in the Mendelian controversies ahead.

Pearson's contribution. While Weldon was working with crabs, Pearson was following the logical lines of statistical inquiry which flowed from his first involvement in Weldon's work: ${ }^{42}$ the measurement of the factors that influence intraracial selection and variability. Three streams, often confluent, can be identified: (a) the analysis of frequency distributions and the development of the theory of skew curves; (b) the study of such fundamental factors of natural selection as reproduction and fertility, selective death-rates and longevity; and (c) the use of the new correlation and regression techniques to study variability especially as it bore on problems of selection and evolution. Each of these flowed on after 1900-the first until the end of Pearson's life. Nevertheless, 1900 is a real turning point: it saw the 'rediscovery', the foundation of Biometrika (see later), the publication of the second edition of The Grammar of Science ${ }^{145}$ - which contains two extra chapters of the distillation of Pearson's views on evolution-and generally it 'marks a phase in the history of biometry'. ${ }^{146}$ These are now briefly discussed. (a) Skew curves. Following his analysis of Weldon's 'double humped' curve Pearson was drawn to consider the general theory of frequency curves and not just as they related to problems in growth and evolution. His first paper ${ }^{42}$ had dealt with dissection of a distribution assumed to be a mixture of normal curves, i.e. a composite of several known homogeneous populations-what he called 'compoundness'; his second paper ${ }^{147}$ dealt with asymmetrical distributions generated from homogeneous material一true 'skewness'. ${ }^{148}$ Both he and Weldon recognized the importance of establishing true skewness, and Weldon for one hoped that if a distribution followed a skew binomial, viz. $(p+q)^{\mathrm{n}}$ with $p \neq q$, the degree of asymmetry would give a measure of the difference between $\mathrm{p}$ and $\mathrm{q}-$ in his interpretation this would be the tendency of the characteristic to vary in one direction rather than the other. He argued that in the event it would be possible to visualize a finite number of causes acting collectively to produce the results, thus justifying his views of small continuous variations controlling evolution. As early as April 1893 he was writing to Pearson on this point. ${ }^{149}$

In this paper ${ }^{147}$ and later supplements ${ }^{150}$ Pearson developed his wonderfully flexible system of frequency curves (Types I-XI)-derived as solutions of a simple differential equation as limits either to the binomial or the hypergeometrical series-which have since proved so successful in graduating data from widely disparate sources, ${ }^{151}$ and which were later shown (Pearson was unaware of this at the time) to represent, under limiting conditions, the sampling distributions of many common statistics used in normal sampling theory. ${ }^{152}$ To establish their generality, Pearson tested these curves against a wide range of biological, medical, economic, and other data and was sanguine as to the results: whereas Weldon saw only evolution, Pearson sought general obedience of all phenomena to his models. (This paper ${ }^{147}$ also laid the groundwork for much of Pearson's applied statistical work in other fields, but these need not concern us here.) Pearson also saw another, more technical, result of skewness, viz. that if the distributions generating the correlation coefficients were skew rather than normal, then the 'theory of correlation as developed by Galton and Dickson requires very considerable modifications'. ${ }^{153} \mathrm{He}$ immediately pursued this line of inquiry ${ }^{80,154,155}$ which he considered crucial to his evolutionary studies, because only by knowing the sampling variation of the statistics obtained could reliance be placed on conclusions drawn from results using correlational methods. If at times he allowed what then appeared as minor numerical 
imperfections to vitiate biologically plausible theories of inheritance and evolution, we should remember that Pearson was pioneering and injecting new methods into a statistical vacuum. Nevertheless, such seeming statistical pedantry only increased the incomprehension and hostility of many biologists.

A further problem immediately presented: how were observed and theoretical frequency curves to be compared ? For this Pearson devised the familiar $\chi^{2}$ test for goodness-of-fit, ${ }^{156}$ a step itself made possible only by his own development of multiple correlation theory. Thus the development of this everyday test may be seen as a practical result of his papers both on regression and on frequency curves.

(b) Reproduction, fertility, longevity, and natural selection. In 1896 Pearson introduced the term 'reproductive selection' to describe the phenomenon where 'one pair may produce more offspring than another and in this manner give through heredity greater weight to their own characteristics'. ${ }^{157,158}$ This was selection by differential birth-rate as distinct from Darwin's 'natural selection' through a differential death-rate. Characteristically he developed this concept in immense detail ${ }^{159}$ and reached the general conclusion (p. 314): 'Fertility and fecundity .... are inherited characters .... and their laws of inheritance ... are with considerable probability those already developed ... for the inheritance of directly measurable organic characters [i.e. they follow the ancestral law]'; and further: 'Not only is fertility inherited, but there can be small doubt that it is closely correlated with all sorts of organic characters... and, without a differential death-rate, the most fertile will form in every generation a larger and larger percentage of the whole population.' Suspension of Darwinian natural selection would not in his view result either in regression to past types or permanence of existing types but would instead give full play to reproductive selection whose demonstrated existence indicated an innate progressive tendency to change. These, and other conclusions, help to explain Pearson's growing attraction to evolution by small successive variations and to inheritance under ancestral law, and provided a scientific basis for his 'social' and 'eugenic' ideas.

Pearson then ${ }^{160}$ turned to consider the WallaceWeismann assertion that duration of life is determined by natural selection, an organism having a (average) life-span which is advantageous to its species: he argued that under this hypothesis longevity would be inherited and there would be kinship correlation in life-span. $\mathrm{He}$ measured father/(adult) son, and (adult) fraternal, correlations for ages at death, ${ }^{161}$ and since these were smaller than expectation on the ancestral law he concluded (p. 293) that selective death-rates existed and 'having demonstrated that duration of life is really inherited we have thereby demonstrated that natural selection [in Darwin's sense] is very sensibly effective among mankind'. The next step, the effect on fertility of homogamy, ${ }^{162}$ was soon tackled. ${ }^{163}$ Pearson considered that if homogamy rather than heterogamy results in fertility then we get a first gleam of light on what may be ultimately of vital significance for the differentiation of species', and concluded: '[my data] show that fertility is not a random character, but depends upon the relative size of the husband and wife, and thus being evidence in favour of genetic [i.e. reproductive] selection'.

Pearson next returned briefly ${ }^{164}$ to reproductive selection, that though it could cause a species progressively to change it could not per se differentiate a species into two groups; for this, natural selection would also be necessary. These and previous results ${ }^{160,163}$ led him to reconsider a crucial part of natural selection, viz. that a differential death-rate would not permanently modify a species if it operated only after the reproductive period. He had already shown ${ }^{160}$ that selective death-rates existed for adults; he (and co-authors) now ${ }^{165}$ obtained positive correlations between fertility and longevity, and concluded (p. 170): 'for the reduction or extermination of stock unsuited to its environment we would have to look largely to selection in the adult state', and (p. 171) 'we thus reach the important result that characters which build up a constitution fittest to survive are also characters which encourage its fertility'. In fact he saw in his conclusions from this caucus of work a mechanism for the gradual differentiation and survival of type.

(c) Correlation and variability with an influence on selection. Pearson wrote many other papers during this period some of which come under this head. Two only will be mentioned: a third ${ }^{163}$ has been dealt with briefly above.

In an article in $1898^{166}$ Pearson used multiple regression to reconstruct the predicted average measurements of extinct races from the size of existing bones and given the interrelationships of bone lengths in an extant race. This was not simply a technical exercise in application of a new tool but a means of testing the accuracy of predictions in evolutionary problems under certain conditions and in the light of evolutionary theories. The following year (with $M$. A. Whiteley) ${ }^{167}$ he gave values for 
correlations between certain finger measurements in women to test theorems connected with the influence of natural selection on the variability of species, particularly on differentiation in local races. This paper complemented an earlier one,${ }^{154}$ and with the work already cited exemplifies both the breadth and depth of his approach to the mathematical study of evolution.

Pearson's studies under (a), (b) and (c) above, and on the ancestral law, represent a body of work of enormous inventiveness, imagination, perseverence, and energy, and one which has had a fundamental and lasting influence in fields far wider than those originally entered. Their later development is outside the scope of this paper; the reader is referred as a starting point to lists of Pearson's papers ${ }^{1,4}$ and, for an idea of Pearson's thoroughness and commitment, to the pages of Biometrika (which he largely edited himself) - perhaps the most personally edited scientific journal of this century. Biometrika was to play a central role in the forthcoming controversies and it is important to understand the circumstances of its foundation, which are now described.

\section{The Foundation of Biometrika}

From his appointment to the Goldsmid Chair in 1884 Pearson's work had been continuous and unrelenting. As well as the great volume of scientific work there were books, articles, essays, and letters in other fields, ${ }^{168}$ including a book on the reconstitution of London University. ${ }^{169}$ It is true that during the nineties he could call on the assistance of such as G. U. Yule, F. L. G. Filon, Alice Lee, and other devoted staff, all of whose help he dutifully acknowledged often by joint authorship; but much of the work and all the writing was his own. Such was his reciprocal loyalty that he often wrote or rewrote papers on data collected by his assistants and which he published under their names alone. ${ }^{170}$ And always there was the teaching: a weekly load of 11 hours in 1884 had become by 1897,16 hours of lectures with drawing office duties and supervision of research students in addition. ${ }^{171}$ Though an inspired and inspiring teacher, Pearson longed for greater freedom for research and he applied for the Savilian Chair of Geometry at Oxford (in 1899) and the Sedleian Chair of Natural Philosophy at Edinburgh (in 1901), and was bitterly disappointed to be passed over: 'I am awfully sick at getting back to this loathsome town [London].... What brutes those Oxford Electors were to condemn me to endless years on London.' 172

In 1900 an incident occurred which was to play a crucial role in the forthcoming controversies.
During the summers of 1889 and 1900 Pearson and Weldon, with their loyal band of helpers, had collected material on which to test the theory of 'homotyposis', i.e. the quantitative degree of resemblance to be found on average between like parts of organisms, the purpose being to compare intra- with interracial variation. Exhaustive counts were made on many species ${ }^{173}$ and the results submitted to the Royal Society on 6 October 1900. ${ }^{174}$ Bateson was one of the referees. He was sharply critical of what was certainly a long and difficult paper introducing a novel, and in his view mistaken, thesis, and when an abstract ${ }^{175}$ was read on 15 November the Fellows were inclined to follow his lead. ${ }^{176}$ What is more Pearson considered that Bateson's strictures 'did not apply to this memoir only but to all my work, that all variability was differentiation, etc. etc. ${ }^{177}$

Weldon and Pearson saw this as the writing on the wall. They were now convinced that the Royal Society would reject their 'biometric' papers and they took this episode as 'a practical notice to quit'. ${ }^{178}$ The very next day (16 November 1900) Weldon impetuously wrote to Pearson: 'The contention "that numbers mean nothing and do not exist in Nature" will have to be fought. . . . Do you think it would be too hopelessly expensive to start a journal of some kind ?'179 Pearson was enthusiastic, enrolled Galton's support, and within a month the title Biometrika was chosen (by Pearson), an editorial written (by Weldon), and circulars issued to enlist support. Weldon, Pearson, and the American C. B. Davenport were to be editors and to their great delight Galton agreed, on 23 April 1901, to be 'consulting editor'. ${ }^{180}$ Thus in the last days of 1900 Biometrika was conceived. ${ }^{181}$

Bateson, however, had exceeded the normal bounds of a referee. Subsequent to the meeting of 15 November 1900 the secretary of the Royal Society (Michael, later Sir Michael, Foster), under pressure from Bateson, took the unusual course of printing, and issuing to the Fellows, Bateson's (adverse) comments before they had seen Pearson's full paper and even before Pearson had been notified of the paper's fate re non-publication. With the approval of the Zoological Committee Bateson's comments-'which directly or indirectly attacks all the biometric work of the past ten years and constituted ... a brilliant by logomachic attack'182 were then published in the Royal Society Proceedings ${ }^{183}$ several months before Pearson's paper, which they strongly attacked, ultimately appeared. ${ }^{184}$ This further annoyed Pearson; any doubts as to the wisdom of the Biometrika project vanished and 'confirmed the biometric school in their determination to start and run a journal of 
their own'. ${ }^{179}$ Thirty years later Pearson wrote: '... with twenty volumes issued of Biometrika one can afford to smile when one thinks of Bateson and Michael Foster as unwitting parents to what they would have considered an unviable hybrid!'185 The first volume was published in October 1901; from then the biometricians had a ready-made vehicle to promulgate their views and this they used to great advantage in the controversies ahead. ${ }^{186}$

On 16 October 1900, ten days after Pearson submitted his homotyposis paper to the Royal Society, Weldon wrote to him:

'About pleasanter things I have heard of and read a paper by one, Mendel, on the results of crossing peas, which I think you would like to read. It is in Abhandlungen des naturforschenden Vereines in Brünn for 1865. I have the R.S. copy here, but I will send it to you if you want it.' ${ }^{187}$

Bateson had already lectured ${ }^{188}$ on Mendel's paper and shortly was to have it translated into English for the first time. ${ }^{189}$ From now the controversy between biometrician and biologist-more narrowly between Weldon and Pearson on the one hand and Bateson on the other-was to enter a new and bitter stage.

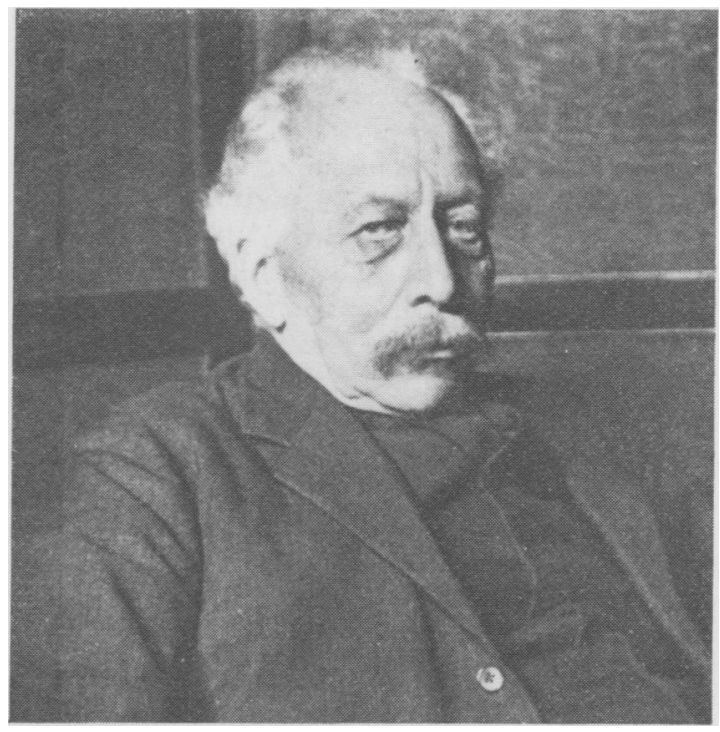

FIG. 4. William Bateson in later life. (Reproduced by courtesy of The Royal Society from J.B.F. (1926). William Bateson, 18611926. Proc. Roy. Soc., B101, i-v.)

\section{PART II: $1900-1906$}

\section{William Bateson and Contemporary Biological Knowledge on Heredity}

William Bateson. By 1900 the biometricians, Weldon and Pearson, had emerged as the active leaders of the ancestrian school; the ageing Galton, though sympathetic, held himself above the fray. If at times and on points of their doctrines one rather than the other would be the spearhead, this was for tactical reasons: always their views were in perfect harmony and their campaign strategy one. There was no such dual leadership among the English biologists ranged against them: William Bateson stood alone as the undisputed champion of Mendelism, towering head and shoulders above all others. Colleagues, assistants, and pupils shared his viewsas did that pioneer of medical genetics and collaborator with Bateson, A. E. Garrod; but though he welcomed the scientific support of their experimental results Bateson fought his stern and uncompromising battles with the ancestrians entirely alone never actively seeking allies nor seemingly needing the moral backing or support of others. His lonely mission was to preach his master's doctrine and convert non-believers to his views.

Bateson was one of the creators of modern genetics. He was a biologist, experimental breeder, and horticulturist, and as such is now less well known to human geneticists than are Pearson and Galton, and

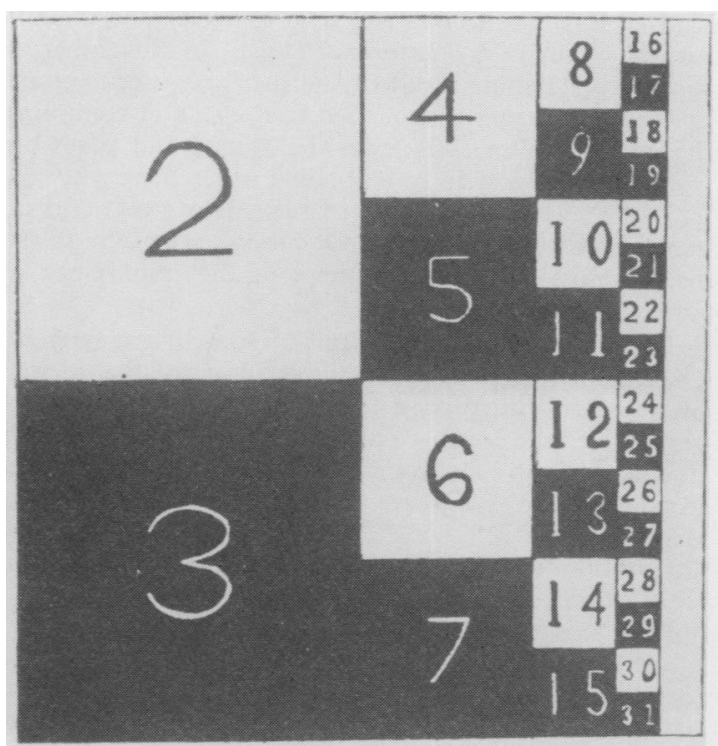

FIG. 5. Graphical representation of Galton's 'law of ancestral heredity'. If the entire square represents the 'inherited faculty' then the average 'contribution to the heritage' of the father (2) and the mother (3) is each one-quarter, that of the paternal grandfather (4) and grandmother (5) each one-sixteenth, and so on, the entire 'ancestral contributions' summing to unity. Originally due to A. J. Meston it was modified by Galton (Galton, F. (1898). A diagram of heredity. Nature (London), 57, 293). 
probably also Weldon. He has been introduced briefly in Part I as a college friend of Weldon but one who became increasingly critical of orthodox evolutionary views and hostile to the biometric ideals culminating in his rejection of Pearson's homotyposis paper. His life and work are accordingly outlined below before the state of biological knowledge on heredity is described and the bitter controversies of the period are detailed.

William Bateson was born at Whitby on 8 August 1861 and died on 8 February 1926. He was the second of the six children of the Rev. William Henry Bateson, Master of St. John's College, Cambridge, and Anna (died 1918), elder daughter of James Aiken, a ship-broker in Liverpool. Bateson won a scholarship at Rugby in 1875, but his career there was disappointing; he was well down the class lists, was unpopular, and was generally miserable except when on nature study at which even then he showed interest and ability. ${ }^{190} \mathrm{He}$ entered his father's college in October 1879 and except for failing Little-go mathematics at his first sitting ${ }^{191}$ had a career of uninterrupted success taking a First in the Natural Sciences Tripos in 1882 and, with a college scholarship, a First again in Zoology in Part II of the Tripos in 1883. Following his important work during the summers of 1883 and 1884 on Balanoglossus under the direction of W. K. Brook at the Johns Hopkins summer laboratory, Hampton, Virginia, ${ }^{192}$ he was elected Fellow of St. John's in 1885 and the following spring left for Asia to study the fauna of lakes and drying-up lake basins, returning finally in the autumn of 1887 . In November he was elected Balfour Student (he had been unsuccessful in 1886), and from then settled to the task of compiling the great body of facts from the animal and vegetable worlds which were to be embodied in his book Material for the Study of Variation (published in 1894) and on which he based his ideas on evolution, especially on the discontinuity of characteristics and the importance of varietal types.

This book was not successful: by some it was ignored, by others savagely attacked though less for the energy, sincerity, and lucidity of the author than for his interpretation of the facts. Teachers rarely introduced their students to it and few copies were sold. ${ }^{193}$ An intended second volume was never written. The book was unfortunately timed: though Bateson urged that his work did not detract from Darwin, this is not how it was seen. He did challenge evolutionary orthodoxy enmeshed as it was in Darwinian concepts of continuity of the 'descent' and the elimination, by intercrossing of 'sports', and in addition he displayed a scientific strictness in experiment and interpretation then alien to many evolutionists. In a prophetic passage in the book he wrote (six years before the 'rediscovery'): 'The only way in which we may hope to get at the truth is by organisation of systematic experiments in breeding ... sooner or later such investigation will be undertaken, and then we shall begin to know.' 194

In 1897 Bateson joined the Evolution Committee of the Royal Society (see page 9). With the help of committee grants he started the poultry and plant breeding experiments which were to bring him into contact with the Royal Horticultural Society - to whom he gave his first lecture on Mendelism ${ }^{195}$-and which were to constitute his main lines of research. But he lacked college status and above all the access to students' minds which teaching would give, and in 1899 he obtained the post at Cambridge of deputy to the Professor of Zoology (Alfred Newton). This enabled him to attract students to his work, and until his death he never lacked a group of enthusiastic and devoted pupils.

Bateson now entered his most fertile period. Much of his work involved breeding experiments of traditional type. But if the methods were old the purpose was new: no longer were the fixity of species and reversion of type the points of inquiry, instead it was the method of transmission of variations-the natural corollary of his views on the importance of varietal types in evolution-and in devising methods for their study. Bateson's thinking closely paralleled that of Mendel ${ }^{196}$ and he was type-cast for the role of main protagonist of Mendelian theories after the rediscovery. ${ }^{197}$ If much of his writing of the immediate post-Mendelian period was polemical and soured by the fierce controversy with the biometricians, by underlining the difference in viewpoints he helped bring them into relief and so on balance contributed to an understanding of the basic issues which divided them. Moreover, unlike Pearson, he used methods all biologists could understand. But he paid a high price: his credibility as an impartial scientist was questioned, and it was some years before his reputation was fully restored. He never regretted it; the end justified the means.

Apart from this interlude Bateson's reputation as an experimental naturalist was now high. In 1900 he followed Weldon as secretary of the Evolution Committee of the Royal Society and the Reports of his experiments under the committee's auspices contained the results of much of his basic work. ${ }^{198-201}$ About this time he also interpreted Garrod's findings on alkaptonuria in terms of it being 'a rare and... recessive character', the first instance of a human trait being correctly interpreted in Mendelian terms. ${ }^{202}$ But at first things were difficult; funds were short and appeals to philanthropic bodies were unsuccessful. His period of immoderacy over Mendelism had told against him. He considered the (paid) secretaryships of the Zoological Association and of the Royal Society and even contemplated emigration, but a small donation ( $£ 150$ per annum for two years from his friend Mrs. Herringham) allowed him to carry on now with R. C. Punnett as colleague. Only in 1906, however, were funds (collected by Francis Darwin) sufficient to allow him to discontinue his 'begging letters'. From now things were easier. Though Sedgwick was preferred to him for the Chair of Zoology at Cambridge in 1907, he was appointed Silliman Lecturer at Yale for October that same year ${ }^{203}$ and the humiliating Readership in Zoology (at $£ 100$ per annum) which he accepted on his return was held for only seven months before his appointment, on 8 June 1908, to the newly founded 
Chair of Biology at Cambridge. ${ }^{204}$ Two years later he accepted the directorship of the newly-established John Innes Horticultural Institute at Merton, near Wimbledon, and remained there until his death in 1926.

Under Bateson's direction the Institute flourished. When he arrived there was only bare land; when he died 16 years later it had become 'probably the best equipped station of its kind in the world'. ${ }^{205}$ His reputation and research programme ensured a stream of students and colleagues; his integrity and humanity ensured their loyalty. Lines of work stemming mainly from his investigations of apparent exceptions to Mendel's rules led to discoveries in somatic segregation, reversion to putative ancestral type, the roguing of certain races of peas, sex linkage, gene interaction, and many others. Just as he had ardently promulgated Mendelism in earlier days now it was his critical faculty which prevented Mendelism from becoming a dogma. But there were failures and false conceptions. Linkage, demonstrated by Punnett and himself experimentally and termed by them 'gametic coupling', was incorrectly asscribed to 'reduplication', i.e. post-meiotic division of the gametes containing the linked traits; only later did Morgan demonstrate the existence and behaviour of coupled genes. ${ }^{206} \mathrm{He}$ was also slow to distinguish the separate nature of factors of phenotype from those of genotype and to the end of his life was overcautious in using results from cytological study to interpret problems in genetics. ${ }^{207}$ And perhaps most important was his ill-fated 'presence-and-absence' theory, ${ }^{208}$ so plausible at the time ${ }^{209}$ but which led logically to the untenable 'unpacking' theory of evolution, ${ }^{210}$ to which he clung tenaciously against mounting opposition until his death. ${ }^{207}$

Bateson was a noble, humane, and inspiring man, dominant but not domineering, and worshipped by his pupils. He won many honours and prizes; F.R.S. in 1894, council member of the Royal Society 1901-1903; Darwin Medallist in 1904, Victoria Medallist of the Royal Horticultural Society in 1911, and Royal Medallist in 1920; President of the Zoology Section of the British Association in 1904, of the Agricultural Sub-section in 1911, of the Association itself in 1914, and PresidentElect of the Botany Section at his death; Silliman Lecturer at Yale in 1907, Fullerian Professor of Physiology in the Royal Institution 1912-1914, Croonian Lecturer in 1920, and Leidy Memorial Lecturer in the University of Pennsylvania in 1922; D.Sc. honoris causa from the University of Sheffield in 1910, and a Trustee of the British Museum in 1922 and Chairman of the Development Commission of the Board of Agriculture 1912, and a member of the University Grants Committee 1919-1920. He declined a knighthood in 1922. With R. C. Punnett he founded the Fournal of Genetics in 1910 and was editor until his death. He was an authority on Oriental art and a successful collector: part of his private collection still hangs in the British Museum. ${ }^{211}$

Bateson married Beatrice (née Durham), daughter of a surgeon at Guy's Hospital, in 1896. Two of his three children-all sons-pre-deceased him; one killed in action in 1918, one by his own hand in 1922 . A sister-
Mary-was an historian, another-Anna-a botanist. His main scientific works were collected and edited by R. C. Punnett; $;^{212}$ a biography (including selected letters and articles) and a volume of collected letters ${ }^{213}$ were published by his wife. ${ }^{214}$

Contemporary biological knowledge of heredity. To many the Mendelian-ancestrian debate is sterile, nugatory, and unintelligible; but this is because it is seen in retrospect and from the security of the modern gene theory of heredity. It was very different at the time. Before 1900, though the mass of data on inheritance was growing rapidly, it had never been brought together into a unified system because the basic principles which would have ensured such systemization were unknown. After 1900 ideas were forged into a coherent particulate theory, but only slowly: Mendel's principles had to be tested, ideas clarified, exceptions to the 'laws' explained, and the whole to be reconciled with cytological discoveries. The issues involved were live ones at the time and can best be judged against the backdrop of existing biological knowledge. We deal very briefly with two aspects: (a) ideas on physiological units of inheritance; and (b) discoveries in cell mechanism and function. ${ }^{215}$

Physiological units of inheritance. Herbert Spencer's hypothesis (in 1864) (16 $^{16}$ that specific characteristics of a tissue are determined by 'physiological units' somewhere in size between molecules and the visible cell-starts the 'modern' development. ${ }^{217}$ These units were theorized as specific, self-reproducing, circulatory, and such that their modification could lead to alteration in bodily parts; they control development and transmit instruction to the cells; the gonads are structures which contain groups of these units in an appropriate state to relay instructions concerning the morphology of the species; and filial resemblance is due to the transmission of these units from the parent. A necessary concept was the inheritance of acquired characteristics ('Lamarckism'), ${ }^{218}$ and though it was to find its full flowering in America ${ }^{219}$ Spencer could be considered as the first of the neoLamarckians. ${ }^{220}$

Four years later (1868) Darwin set out his sole account of 'the provisional hypothesis of pangenesis', ${ }^{49}$ though he had sent the MS to Huxley in $1865 .{ }^{50}$ The theory, which is essentially preSocratic, may have owed something to Spencer: more likely it was Darwin's independent attempt to explain variation and inheritance about which Origin had said very little. Darwin postulated that all heritable properties are represented in the somatic cells by numerous invisible particles ('gem- 
mules') which increase by division. Body cells continually give off gemmules which are 'dispersed throughout the whole system', collect together, 'in a dormant state', in the ova and spermatozoa, and are again dispersed in the offspring to corresponding organs whose nature some of them control, others being 'undeveloped' until activated by a suitable environment. These gemmules can transmit all somatic information to the germcells; thus acquired characteristics can be passed on to the offspring-though this is not invariable. Variation is due to comingling of the gemmules of the parents and by modification in the parental cells. Marked structural defects, e.g. loss of a limb during life, are not reproduced in the offspring because the germ-cells already contain gemmules from the part before its loss. This hypothesis did much to support the concept of blending inheritance, the biological conception of inheritance being then closely analogous to the legal one: the parents handed on the average of their characters in the same way as they handed on the average of their belongings whether inherited from their own parents or amassed during life!

The reception of pangenesis was mixed and complex; but the concept was undoubtedly viable. Wallace wrote: 'The hypothesis is sublime in its simplicity and the wonderful manner in which it explains the most mysterious of the phenomena of life. To me it is satisfying in the extreme. I feel I can never give it up, unless it be positively disproved, which is impossible, or replaced by one which better explains the facts, which is highly improbable. ... I consider it the most wonderful thing he has given us, but it will not be generally appreciated.'221 The questioning Galton seized on it immediately and set out to demonstrate it by experiment. He erroneously interpreted Darwin to mean that the gemmules circulate and even propagate in the blood ${ }^{222}$ Darwin had merely supposed direct diffusion from cell to cell and in fact had considered mainly protozoa and plants which have no blood, ${ }^{223,224}$ though he had not corrected Galton in their regular correspondence at the time ${ }^{225}$ - and he tried to demonstrate their effect by blood transfusions between rabbits of different colours, and their subsequent breeding. ${ }^{226}$ In his view, though not in Darwin's, ${ }^{227}$ the results refuted the hypothesisand with it the basis for inheritance of acquired characteristics; yet Galton retained the idea of submolecular particles as messengers of inheritance and instruction and this he incorporated into his theory of 'stirp'.

At least as early as 1869 Galton was feeling his own way towards a particulate theory of heredity which specifically disallowed inheritance of acquired characters; his rabbit experiments only confirmed some of his views. ${ }^{228} \mathrm{He}$ foreshadowed his theory of 'stirp' in a paper in $1872^{229}$ and first defined the term in $1875^{230}$ as expressing 'the sum total of the germs, gemmules or whatever they may be called, which are to be found, according to every theory of organic units, in the newly fertilized ovum-that is in the early pre-embryonic stagefrom which time it receives nothing further from its parents, not even from its mother, than mere nutriment'. ${ }^{231}$ With suitable modifications and some special pleading he showed that it could explain known facts: ${ }^{232}$ its main importance here is that it denied (except very occasionally) the inheritance of acquired habits or characters; it offered a theoretical basis for the relationship between parent and child and on which the ancestral law was built; it introduced the concept of hereditary continuity by 'stirp', i.e. by a substance within the body; and that it adumbrated principles which Weismann restated in his theory of the continuity of the germ plasm.

Weismann, from $1883,{ }^{233}$ expanded the theme of continuity in the light of new cytological discoveries. Essentially he theorized that the now visualized chromatin substance of the cell nucleus halves its operative content when forming a germ cell, the residue being the polar body. This operative content he termed germ-plasma or germ-idioplasma ${ }^{234}$ (more usually germ-plasm) which has a definite chemical and molecular structure. Germ-plasm is in the visible idants - which may be said to correspond to the chromosomes - and these are made up of ids (identifiable with the chromatic granules) which in turn contain determinants constructed of the smallest, ultimate living units, biophors: in fact a pyramidal structure of ascending size from atomic biophors to visible idants. Ids of the same species are almost identical but changes may occur to the constituent determinants which contribute to intraspecies variation. The determinant is then the basis of the Weismann concept on which he explains such factors as the inheritance of variations, varietal types, mimicry, and others. The gonads contain all the determinants necessary for the production of a new zygote, and the integrity, continuity, and representative character of the germ-plasm is ensured by supposing that one of the daughter cells of the first zygotic division forms the germ cells, and the other the body, of the organism. Thus the somatic and germ stem-cells are immediately separated: the former originates the mortal body and the latter the germ cells which contain the immortal and undifferentiated germ-plasm. There 
were many complexities and refinements, but this was Weismann's theory which he set out and developed in several publications and an address at the British Association meeting in $1887^{235}$ before his main works. ${ }^{55,236}$

Weismann's doctrine, though in essence an extension of Galton's, was wider in concept. Unlike Galton-who was postulating mainly a theory of heredity-Weismann was also suggesting the nature and action of a particulate structure and its place in evolution. His work was a watershed: Lamarckism was utterly rejected, ${ }^{237}$ evolutionary thought stepped the path leading towards genetics, and the particulate hypothesis became more coherent with each cytological discovery, some Weismann's own. Coeval with his work was that of de Vries who during the eighties developed his ideas of 'pangenes' which he stated fully in 1889. ${ }^{238}$ De Vries theorized swarms of living units in all cells but, unlike other conceptions, these units are of many different kinds. They are concentrated in the nucleus, some entering the cytoplasm to influence cytoplasmic reactions, and are self-replicating with occasional errors giving rise to varietal types. Recombinations of these units contribute to variation, but alternative stateslater 'alleles'-are excluded. He called these units 'pangenes' after Darwin's 'pangenesis', though gemmules and pangenes were conceptually different. De Vries, by following his thinking towards experimentation, took the path pioneered by Mendel and led him ultimately to Mendel's work and his own parallel discoveries in mutation ${ }^{239}$ and segregation. ${ }^{240} \mathrm{He}$ was unique in that he reached his particulate theory deductively and confirmed Mendel's rules, before 1900, inductively by experiment on the largest unit of all, the phenotype.

Cell function. Associated with the development of the particulate theory were advances in knowledge of cell structure and function: it was no accident that, for example, Weismann's theory was formulated contemporaneously with the discovery of the cellular processes of fertilization and the maturation of the germ cells. Chromosomes, their numerical constancy in species, and mitosis had all been discovered in the early eighteen-seventies, and their structural consistency through generations in 1885 by Rabl. Van Beneden in 1881 and Boveri in 1888 showed that the ovum and the sperm each contribute half the diploid constitution and at about the same time the process of meiosis was first worked out. The microscopical structure of the chromosomes with constituent 'chromomeres' and 'chromioles' was developing in the eighteen-nineties by which time most cytologists accepted that the nucleus con- tained the material of heredity. By the end of the century haploid and diploid phases had been identified in many species, fusion of gametes observed, and meiotic division seen to be constant and universal. $^{241}$

All these discoveries changed the biological standpoint substantially: biology was now more receptive to Mendelism-which partly explains the timing of the 'rediscovery'. ${ }^{242}$ Before Mendelian principles could be given a physical rationale, however, two problems had to be solved. On Weismann's theories, then dominant, all chromosomes were in effect considered unpaired, and also more or less equivalent-each idant containing all the determinants necessary for development of the individual. The first step was by Boveri in 1902 who showed, on the sea urchin, that this latter was not the case. Each chromosome did not carry the totality of hereditary material; different chromosomes carried different 'Mendelian factors'. ${ }^{243}$ What was now required was to show that the chromosomes in the diploid nucleus were paired with one member of each pair derived from either parent. In the same and the following year, Sutton ${ }^{244,245}$ provided this evidence in the lubber-grasshopper: 'I may finally call attention to the probability that the association of paternal and maternal chromosomes in pairs and their subsequent separation during the reducing division as indicated above may constitute the physical basis of the Mendelian law of heredity.'244 This-the Sutton-Boveri hypothesis ${ }^{246}$ - was the synthesis, the chromosomal theory of inheritance: visible units could be seen to behave in a manner analogous to that deduced for the small material elements, the Mendelian 'factors'. In the same year Johannsen-who later was to introduce the term 'gene' ${ }^{247}$-developed the concept of the pure line. ${ }^{142}$ The path to the gene theory now lay straight ahead.

\section{The Development of the Controversy}

We have seen (Part I) that Bateson and Weldon had drifted into enmity after the Cineraria letters ${ }^{11-117}$ and Weldon's unfavourable reception of the ideas expressed in Bateson's book $;^{109}$ that Pearson and Bateson, by training and outlook antipathetic, had come into open contention over the homotyposis paper $;^{174}$ and that their joint membership of the Evolution Committee had increased this dissonance. Now, with the disinterment of Mendel's work, discord gave way to open hostility as the lines became clearly drawn: Bateson championed Mendelism as 'a zealous partisan';248 the biometricians were variously intent on its 
subordination to, or treatment as a trivial exception from, the universality of the ancestral law.

The first exchanges. The opening shots were fired by Weldon. Spring 1900, which found Bateson reading Mendel, found Weldon immersed in his pedigree moth breeding and Shirley poppy growing:249 'a solid eight hours daily of stable-boy work through the whole summer [1899], and through the Easter vacation [1900], with decent statistical work between' ${ }^{250}$ Journeys to Europe to collect snails of the Clausilia species followed, but only two fragments of publications resulted. ${ }^{251,252}$

Weldon first read Mendel in the autumn of $1900 ; 187$ but from then he studied Mendelism closely. ${ }^{253} \mathrm{He}$ had agreed to write a critical bibliography of relevant papers-because 'his [Weldon's] study of Mendel had led him to a very great number of such papers dealing with inheritance'254_but his thoroughness militated against speed and he was overtaken by events and the work was never published. His wide reading, however, had shaken his confidence, or rather confirmed his lack of confidence, in the general application of Mendelism and he submitted a controversial critique to Biometrika which was published in the January edition in 1902. ${ }^{255}$

In this article-which was unpolemical and did not challenge Mendel's integrity or results but only the interpretation and universality of the findings ${ }^{256}$ -Weldon tested Mendel's results against expectation on assumptions of phenotype dominance and independent assortment of three (of the seven) chosen characters, and found close agreement. ${ }^{257}$ He then considered 'dominance' and 'segregation' and found incompatibilities with other work. With dominance he was on good ground-the 'dominance' by which Mendel selected his seven 'differentiating characters' was even then under challenge and Mendel's selection considered to be a combination of coincidence and superficial examination $^{258}$ - and though Bateson was to dismiss ${ }^{259}$ the arguments and consider Weldon's selection of examples biased, much of the article seems reasonable. Weldon concluded: 'These examples... seem to me to show that it is not possible to regard dominance as a property of any character, from a simple knowledge of its presence in one or two individual parents. The degree to which a parental character affects offspring depends not only upon its development in the individual parent, but on its degree of development in the ancestors of that parent' (our italics). On segregation Weldon did not rule out 'simple segregation ... in particular cases', but did not accept its universality. He concluded:
'Taking these results ... we can only conclude that segregation of seed-characters is not of universal occurrence among cross bred Peas, and that when it does occur it may or may not follow Mendel's law. The law of segregation, like the law of dominance, appears therefore to hold only for races of particular ancestry. . . . The fundamental mistake which vitiates all work based upon Mendel's method is the neglect of ancestry and the attempt to regard the whole effect upon offspring, produced by a particular parent, as due to the existence in the parent of particular structural characters. . .'255

To Weldon, the 'role of ancestry' remained inviolate and the very existence of Mendel's 'principles' (Mendel did not speak of 'laws') unproven.

Bateson read Weldon's article on Saturday 8 February 1902, with 'regret approaching to indignation'. ${ }^{260}$ As Mendel's ardent disciple his mission was clear; it was to exorcise this heresy before all were corrupted. ${ }^{261}$ It would not be enough simply to demolish the arguments; Weldon himself, the perpetrator, the only 'naturalist of repute... to rise against him [Mendel]' ${ }^{260}$ would have to be destroyed. He settled at once to the task and completed his fiercely polemical Defence the following month. ${ }^{262}$ Despite its emotiveness and offensive tone ${ }^{263}$ there is no doubt that Bateson was largely successful, at least on the scientific plane: Defence was quickly sold out and in the author's view had so well served its purpose that it was not reprinted.

In Defence, Bateson countered many of Weldon's arguments, particularly those based on the horticultural literature, but left others intact. Six months later Weldon replied, in the now inevitable rejoinder, ${ }^{264}$ to both Defence and Bateson's First Report to the Evolution Committee. ${ }^{198} \mathrm{He}$ debated points systematically - concentrating particularly on the seeming weakness of Bateson's dismissal of phenotype variation in a genotype as unimportant to Mendel's 'principles'; but his article is more noteworthy for the absence of any real constructive dialogue with Bateson. For in fact they were speaking different languages. To a naturalist inheritance dealt with the constancy of specific or racial types (and of sexual characters), experiments were in crosses between races viz. hybridization, and the results were amenable to the simplest arithmetic $;^{191}$ on the other hand the biometrician-ancestrian was more concerned with whether knowledge of a character in the ancestry allows prediction as to that character in the offspring to a degree greater than chance, viz. 'individual heredity', and this could most properly be measured by techniques for multiple association of attributes, particularly multiple regression. Again, the biologist was concerned with interpreting breeding results in terms of some physiological theory of inheritance; the ancestrian (particularly 
Pearson) used his formulae as mere empirical predictive models which described observed phenomena without necessarily postulating any physiological mechanism at all. And moreover what chance had any non-mathematical biologist to really understand the basis of the ancestral law, viz. multiple regression, with its independence of any biological rationale and its appeal to multidimensional models and the rather abstract concept of hyperplanes? And in addition to these general considerations there were individual shortcomings. Bateson failed fully to grasp that Mendel's advances over his predecessors- that he crossed closely allied varieties not different species (which would differ from each other in many factors) and thus made sense of many of the results of hybridization and formed a basis for the understanding of the evolutionary process-was not antagonistic to Darwinian theories, ${ }^{265}$ and he therefore considered the case for evolution by discontinuous 'jumps' as against that by inheritance of small continuous variations more or less proved; while Weldon for his part hardly seemed to understand that segregation could explain a wide range of phenomena, considered Mendelian inheritance an unimportant exception to the ancestral law, laid too great an emphasis on discordance between computed and theorized values of the ancestral constants, and undervalued the importance of mutations. ${ }^{266}$ Add to all this the incompatibility in outlook and scientific philosophy between the main protagonists, the pugnaciousness, sagacity, and taste for controversy which they shared, and Pearson's weakness for teaching biology to biologists and his arrogant insistence that only statistically-trained minds could grapple with evolutionary problems and evolution itself too serious a subject to be left to evolutionists, and all the ingredients for mutual incomprehension and bitterness were present to a high degree. ${ }^{267}$

In retrospect the lines which were now drawn were inevitable. But the scientific viewpoints, if not the protagonists, were not necessarily incompatible, as particularly Bateson claimed, and attempts to reconcile them were soon made.

The search for common ground. The first attempt was not made by any of the combatants but by Udny Yule. ${ }^{268}$ Yule saw clearly that the ancestral laws (of regression and reversion) described results of intraracial heredity of respectively 'scalar variables' (e.g. height) and 'attributes' (e.g. eye-colour), and that Mendel's principles held for specific characters during hybridization-albeit between closely allied varieties; two different situa- tions. He was also uncommitted (he accepted both the 'Law of Ancestral Heredity' and 'Mendel's Laws' to be 'true'); ${ }^{269}$ his problem was 'to delimit their respective spheres, and shew in what way the one type of law may pass into the other, or the two even coexist'. 270 In fact he was prepared to examine whether continuous variation in the phenotype could arise from changes of the genotype either due to 'continuous variation of the elements of the germ cell ... or ... the compounding in some way of the discontinuous variations of a number of such elements' (p. 235). Using a general approach he adumbrated some of the later work of Pearson ${ }^{140}$ and Fisher ${ }^{270}$ on kinship correlations of quantitative characters assuming random mating and the additive and equal action of a number of genes ('units') each following Mendelian segregation. He concluded: 'Mendel's Laws and the Law of Ancestral Heredity are not necessarily contradictory statements ... but are perfectly consistent the one with the other and may quite well form parts of one homogeneous theory of heredity' ${ }^{271}$ and again (p. 227): 'The value of the work of Mendel and his successors lies not in discovering a phenomenon inconsistent with that [ancestral] law, but in shewing that a process, consistent with it, though neither suggested nor postulated by it, might occur.' We will return to this line of development later.

Meanwhile, Pearson and Weldon were immersed in mutual problems of inheritance and evolution. Careful reading shows that they were not unreceptive to Mendelian ideas: in fact their comments were directed as much at what they saw to be a too facile and universal acceptance of Mendelism and 'a certain looseness of logic, a want of clear definition and scale, an absence of any insight into how far the numbers reached really prove what they are stated to prove', ${ }^{272}$ as at the validity of the Mendelian principles themselves. They insisted that to be accepted any scheme of individual inheritance must lead to conclusions consonant with statistical analysis of large-scale observations, and it was lack of this that caused them concern. As a field naturalist Weldon's approach was to collect his own biological data; and the remaining few years of his life were spent in extensive field work, instigating mice breeding experiments (conducted subsequently by A. D. Darbishire and others including Weldon's wife-see below), and bringing together all the results in a book on inheritance-which was unfinished at his death. Pearson for his part was to deal with the mainly statistical problems evolutionary data posed, though only as one facet of his general statistical work. It was the importance of this statistical development coupled with Weldon's early death (in 
1906) which made Pearson the dominant partner in the years ahead.

Pearson's first article ${ }^{273}$ after the publication of Yule's paper ${ }^{268}$ was written without knowledge of Yule's results. In it he restated, with new data, the ancestral law and the basis of Mendelism and he enunciated the criteria which the latter must fulfil to be considered a better explanation than the former. There is no evidence that he considered them to be necessarily incompatible hypotheses yet neither does the paper suggest that he then held views concerning the means of their possible synthesis. ${ }^{274}$ But he went further. He saw the need for 'new and crucial experiments ... made with much greater caution and closer quantitative definition of the categories employed', ${ }^{275}$ and by suggesting that the 'laws' governing inter- and intraracial heredity may be closely related he signalled the paths which the biometricians must take: obtain better data; and try to bring all heredity under a single 'law' by a synthesis of Mendelian and Galtonian principles. The former-data collection-he left largely to Weldon; the latter-the path to an attempted synthesis-he had to walk usually alone because of the mathematical complexities involved.

The statistical approach. Yule's paper ${ }^{268}$ influenced Pearson but it was Weldon who really pointed the priority they should give to studying the relation between Mendelian theory and the ancestral law. ${ }^{276}$ They worked together on the problem during the summer of 1903 and the resultant paper $^{140}$ was the first detailed study of the problem which Yule had adumbrated.

Basically Pearson examined whether such a somatic feature as stature could be determined by a large number of equally important genes acting additively and without relative dominance and such that the somatic variation among sibs could be due to the segregation of those genes for which the parents were heterozygous. He did not, of course, speak at that time of genes but of a 'pure gamete theory' with gametes containing A and a 'elements': 'The present study is an attempt to see how far one generalized pure gamete theory leads to results in accordance with the law of regression and the known nature of the distributions of offspring in populations.' 277 More specifically, he examined the correlations between $n$ equally important Mendelian pairs on the above assumptions and supposing the population to have arisen from a series of initial hybridizations and subsequent random mating, equal survival and fertility, and showed (a) that a character in an ancestor and offspring would be correlated, decreasing geometrically as the genera- tion interval increased arithmetically, and (b) that the regression of offspring on any ancestor with respect to the character would be linear. $\mathrm{He}$ reached theorized values of the correlation coefficient of $\frac{1}{3}$ for parent/offspring, $\frac{1}{3}\left(1 / 2^{\mathrm{m}}\right)$ for the $m$ th great-grandparent/offspring, and 0.4 for $\mathrm{sib} / \mathrm{sib}, 278$ which were "very sensibly lower than the valueabout 0.5 - [for parental and fraternal correlations] found from recent investigations in man' (p. 77). $\mathrm{He}$ also demonstrated, in his Proposition II, the equilibrium principle ${ }^{279}$-which was dealt with later more fully by Hardy ${ }^{280}$ and Weinberg ${ }^{281}$ - and discussed the place in his scheme for extreme varietal types.

Misconstruction of Pearson's conclusions has contributed to the erroneous idea that Pearson more or less completely rejected Mendelism, at least as then presented, ${ }^{282}$ and the results should therefore be stated carefully. Pearson dealt with the correlation between somatic characters in offspring and ancestors in a Mendelian population 'more general in that I supposed the character to depend upon $n$ couplets and not a single Mendelian couplet, less general in that I supposed the population to have arisen from a series of initial hybridizations and not from a mixture ... of hybrids and members of two pure races in any proportions'. ${ }^{283} \mathrm{He}$ examined the scheme $A_{r} a_{r} \times A_{r} a_{r}$ (where $A_{r} a_{r}$ is any allelic pair in the zygote $A_{1} a_{1}, A_{2} a_{2} \ldots A_{n} a_{n}$ ) under the conditions stated above ${ }^{284}$ and found that it led to the linear regressions, correlation constants, and geometric progression of these constants as stated under (a) and (b) in the previous paragraph. On these findings Pearson wrote: 'We thus see that a generalised theory of the pure gamete would be of very great advantage if it could be accepted. It would lead to a system of inheritance ... which ... . would be essentially the same as that which had been biometrically developed not from theoretical hypotheses, but from the statistical description of observed facts in populations. ${ }^{285}$

This was plain enough, but two questions needed answers: (a) would the discrepancy between observed and theorized kinship correlations (the former were higher) and the universality and rigidity of the theorized values, invalidate the theory; and (b) what exactly was the relation between Pearson's 'pure gamete theory' and Mendelism? As regards (a), Pearson considered that the discrepancy in the coefficients was not a disqualification; ${ }^{286}$ instead, better concordance could be obtained either in amending the assumptions of the Mendelian theory considered-to some new 'neo-Mendelian formulae' - or (p. 86) in introducing real-life complexities-homogamy, differential fertility, pre- 
potency-to his simple theoretical scheme. As regards (b), Pearson wrote: 'We reach pure Mendelianism by making our protozygotes [AA] "dominants", our allozygotes [aa] "recessives", and our heterozygotes "hybrids of dominant character". In so far as our theory of pure gametes replaces protozygote, allozygote, and heterozygote by "dominant", "recessive", and "hybrid with dominant character", it becomes a generalized Mendelian theory, but only in this case. ${ }^{287}$ In fact the two were very close indeed; but new cytological and breeding discoveries soon complicated this simple picture and led to much pedantic and nugatory wrangling which it would be unprofitable to trace. In short, Pearson considered that pristine Mendelism led directly to the ancestral law and was not antagonistic to it; concordance of theorized with observed values could come from qualifying either Mendelism or the simple assumptions on which the theorized correlations were reached. This was probably as far as any prudent person could then go given the uncertain standing of incomplete dominance, and the lack of experimental evidence of the theoretical concepts of multiple allelism and the additive effect on a character of independently segregating genes. ${ }^{288}$ In fact up to 1906 the only qualification advanced for raising the theorized kinship correlations was to the vulnerable concept of dominance. ${ }^{289}$ This was by Yule $^{282}$ who again emerged as a pioneer of the synthesis of ideas on heredity: 290 complicating Pearson's assumptions required the will and statistical resource of Fisher and came much later, in $1918 .{ }^{270}$

Breeding studies. Concomitant with this approach were Weldon's breeding experiments and field studies planned primarily rigorously to test existing laws of inheritance but with the more distant objective, never far from Weldon's and Pearson's thoughts, of formulating some general 'law' which would embrace the entire spectrum of heredity 'from simple Mendelism at one end of the range and blended inheritance at the other'. ${ }^{291}$ Of these the mice breeding experiments and the racehorse coat-colour data were perhaps the most important. They inspired controversy and yielded what then seemed important facts, though in retrospect the sterility of the arguments and the length of disputatious pedantry to which the combatants were prepared to go to defend their fundamentalist positions are perhaps the most remarkable facts of all. These studies are now described.

Mice-breeding experiments. Early in 1901 Weldon read the work of von Guita ${ }^{292}$ on crossing Japanese 'waltzing' mice with an inbred strain of albinos, but considered the results to be inconsistent with Mendelian views. ${ }^{293} \mathrm{He}$ decided to experiment himself and he collected Japanese mice, pure bred them for a year, and then commenced hybridization experiments which he entrusted to A. D. Darbishire. ${ }^{294}$ The first results were published in November $1902^{295}$ and February $1903^{296}$ and dealt with the first two generations after hybridization. Darbishire thought them puzzling: many of the segregation patterns were Mendelian but Darbishire was unable to explain, on Mendel's principles, the behaviour of coat-colours in the non-albino genotypes (he seemingly considered that on simple Mendelism the coat-colours should have fallen into clear qualitative categories), and he dismissed Mendelism for the eye-colour heredity despite typical $F_{1}$ and $F_{2}$ segregation because of a correlation between eye- and coat-colour in the $\mathrm{F}_{2}$ hybrid when he would have expected no association.

Bateson was fast into the attack. Concentrating on the eye-colour results (he dismissed the coatcolour findings as 'though exceedingly important they are too complex for consideration in a few lines ... but did space permit I should be glad to discuss these facts as far as they go'), he suggested that these were consistent with the mating of $\mathrm{GG} \times \mathrm{G}^{\prime} \mathrm{G}^{\prime}$ genotypes where the homozygous forms are pink-eyed and all heterozygous forms have coloured eyes. ${ }^{297}$ This didn't satisfy Weldon, Darbishire's mentor, who now took charge. He supposed that Bateson's reluctance to deal with coat-colour was to avoid compromising the Mendelian arguments and he asked why the $G^{\prime} G^{\prime}$ forms in $F_{2}$ did not always have the same coat-colour as the grandparent $G^{\prime} G^{\prime}$ forms: they need not have had but seemingly Weldon considered both eyeand coat-colour to be under the same gene control. ${ }^{298}$ In a patronizing reply Bateson dealt briefly with coat-colour and considered all Darbishire's segregation results to be in 'punctilious agreement with Mendelian prediction'. ${ }^{299}$ Weldon dissented, ${ }^{300}$ Bateson came again, ${ }^{301}$ Weldon then accused Bateson of twisting Mendelism so that 'his [Mendel's] name is made to shelter almost any hypothesis, and almost any experimental test is evaded', ${ }^{302}$ until finally these increasingly futile and carping exchanges were mercifully stopped by the editor of Nature who returned unpublished yet another letter from Bateson ${ }^{303}$ and refused to accept any more correspondence on the subject. But if the columns of Nature were closed to them both those of Biometrika were open to Weldon; and in an article written just before the final exchanges in Nature he dealt in detail with Darbishire's results and for good 
measure yet again with Mendel's 'principles' and Bateson's revisions and interpretations of them. ${ }^{304}$ Bateson again sought space in Nature but without success. ${ }^{305}$

That same month (May 1903) Darbishire published further results of his mice breeding. ${ }^{306} \mathrm{He}$ was again unable to interpret these in terms of Mendelism; instead he considered that they accorded with some hypothesis of ancestral determination. ${ }^{307} \mathrm{He}$ continued the breedings and in January 1904 brought all the results together. ${ }^{308}$ His conclusions were as equivocal as before: the binary traits waltzing/not-waltzing, coloured coat/ white coat, and pink-eyed/coloured-eyed, segregated in Mendelian proportions; but the correlations between in turn coat-colour in hybrids and descendants on the one hand and the ancestry of their albino grandparents on the other, and the behaviour on crossing of the 'extracted' phenotypes, refuted 'gametic purity' and to Darbishire rendered 'Mendelian principles in their widest sense' untenable. Ancestral contributions were seemingly important, but he drew no conclusions as to the general applicability of the Galton-Pearson geometric law of inheritance. ${ }^{309}$ And so the matter stood, but only for a time: another arena, and new sets of results on which to continue the old controversy, were needed and were soon to be found.

In August of that year (1904) the British Association met at Cambridge. Bateson was President of the Zoology Section (Section D) and his address was a direct challenge to the ancestrians. He spoke as one so confident in the already established truth of Mendelism and his own interpretations of it that dissent was futile. He hardly deigned to bring the ancestrians under notice, loftily dismissing the 'gross statistical method' in illuminating heredity as 'a misleading instrument ... the imposing Correlation Table into which the biometrical Procrustes fits his arrays of unanalysed data is still no substitute for the common sieve of a trained judgement'. 310 The following morning's session ${ }^{311}$ contained 'Mendelian' papers on crossing flowers (by Miss E. R. Saunders) and breeding rabbits (by C. C. Hurst)-both authors were Bateson's close colleagues-and a paper by Darbishire again describing his mice breeding results. Darbishire still bravely remained uncommitted: 'Some of the facts which have come to light seem confirmatory of the Mendelian interpretation... while others are describable in terms of either Galton's or Pearson's formula of ancestral inheritance. I do not think, therefore, that Law justified in forming an opinion on the question of the relative validity of these two interpretations of the facts already observed, and until more data have been collected I do not propose to do so.'312

In the discussion Weldon, speaking to an overfilled hall and 'with impassioned eloquence, beads of sweat dripping from his face', ${ }^{313}$ attacked Bateson's platform. How could gametic purity and Mendelism explain such phenomena as (in modern terms) phenotype variation in identical genotypes, e.g. the wide range of hair concentrations in the hybrid 'hairy' variety of Lychnis dioica, and how could it explain reversions to remote putative ancestors? And he made other points. He concluded: 'until further experiments and more careful descriptions of results were available, it was better to use the purely descriptive statements of Galton and Pearson than to invoke the cumbrous and unundemonstrable gametic mechanism on which Mendel's hypothesis rested'. ${ }^{314}$ Yet despite his advocacy his points appeared unimportant and his arguments laboured, and Bateson, holding aloft a volume of Biometrika as 'patent evidence of the folly of the biometric school', ${ }^{315}$ concluded: 'The Mendelian theory had begun to co-ordinate the facts of heredity, until then utterly incoherent and contradictory ... [I have] no doubt of the result.'314 Pearson, in conciliatory vein, then stressed that he had recently shown that the two schools of thought were not incompatible ${ }^{140}$ and suggested a truce to controversy for three years and for further work since the problems 'could only be settled by investigation, not by disputation'. ${ }^{314}$ But the meeting was in no mood to temporize and the combatants were encouraged to 'fight it out'. ${ }^{206,314}$ This pleased Bateson, did not displease Weldon, but, partly at any rate, saddened Pearson who of the three was the most detached, recognized that controversy with Bateson soon became mere timewasting wrangling, ${ }^{316}$ and had many other lines of work. Furthermore, he saw that Bateson had no inclination to recognize the part statistics must play and consequently would never understand that Mendelism supplied missing parts to Darwin's doctrines and was incapable of convincingly framing any evolutionary theory of his own. The Cambridge meeting was a watershed: thereafter Mendelism became news and though much opposition lay ahead the columns of periodicals were increasingly open to its views and there was no danger of it being 'squelched out through apathy or ignorance'. ${ }^{206}$ But this did nothing to blunt the edge of the controversy: if anything it sharpened it. Bateson was now in full cry and the excitement of the contest was a stimulant to Weldon's vibrant character and 'seemed to brace [him] to greater intellectual activity and wider plans'. ${ }^{315}$ 
Coat-colour in horses. During the next twelve months Weldon and Bateson continued their experimental work. There was little direct controversy: both were content to consolidate their positions and prepare for the next fray. ${ }^{317}$ This came in November 1905 and involved the horticulturist and close colleague of Bateson, C. C. Hurst. Hurst, with Bateson's approval, submitted a paper to the Royal Society on coat-colour inheritance in thoroughbred horses and this came under the immediate attention of Weldon who as Chairman of the Zoological Committee was responsible for acceptances. Data on coat-colour, particularly of horses, ${ }^{318}$ had been crucial in the development of the ancestral law, and now Hurst, using much the same source material (Weatherby's The General Stud Book of Race Horses), was suggesting that the results were consistent with Mendelism and 'fail to give any support to Professor Pearson's [contrary] statement.'319 Weldon accepted the paper, but in five weeks between acceptance (4 November) and presentation (7 December) he zealously threw himself into scrutinizing the stud books (20 large volumes) so as to be able to answer Hurst: 'I can do nothing else until I have found out what it means.... The question between Mendel and Galton's theory of Reversion ought to be answered out of these. ${ }^{320}$

In the discussion of Hurst's paper, Weldon emphasized the occasional birth of bay and brown foals from matings of (recessive) chestnut parents as refuting a Mendelian interpretation; but Hurst stood firm and with no good evidence blandly dismissed these exceptions as mere errors of entry in the stud books. Weldon was jubilant at this lame explanation and rushed to prepare his conclusive rebuttal. Bateson for his part was furious with Hurst for playing into Weldon's hands and he made Hurst withdraw the paper. Weldon's article was duly 'read' on 18 January $1906 ; 3^{321}$ but Hurst and Bateson had been busy in the Christmas vacation and in the discussion were able to dismiss many of the alleged births of bay or brown foals to chestnut parents as probably true errors arising from often arbitrary classification of colour of stillbirths. Only one substantial problem remained-Ben Battle, a chestnut stallion who had sired many bay foals from chestnut mares. Here Hurst pulled off a coup by establishing from other sources that Ben Battle was not chestnut; if this entry in The General Stud Book could be incorrect so also could others. The day was saved, a note was added to the original paper, ${ }^{319}$ and Bateson, much relieved, recommunicated it for publication in February 1906. ${ }^{322}$

Weldon was disappointed but not defeated. He considered these exchanges prefatory: he would study The General Stud Book more closely. But his exceptional intellectual vigour and stamina now battled against physical enervation and he accepted advice to recuperate in Rome. The General Stud Book, however, went with him and remained with him on his return to an Easter vacation at Woolstone, appropriately within sight of White Horse Hill. ${ }^{323}$ On 10 April he contracted influenza but insisted on fulfilling engagements in London on the next two days. He collapsed while at the dentist and died of pneumonia on Good Friday, 13 April, aged 46.

Weldon was mourned by all. Galton felt 'the terrible and disastrous blow... and shall feel the void he has left for probably the rest of my life', ${ }^{324}$ and at 84 went from his sick bed to the funeral. Bateson was no less shocked and wrote to his wife: 'To Weldon I owe the chief awaking of my life. It was through him that I first learnt that there was work in the world which I could do. Failure and uselessness had been my accepted destiny before. Such a debt is perhaps the greatest that one man can feel towards another; nor have I been backward in owning it. But this is the personal, private obligation of my soul. ${ }^{325}$ But to Pearson the loss was irreparable and left 'almost desolation' ${ }^{326}$ 'how mentally refreshing it was to me being near him for a few weeks and how it sent me back fit for work with new vigour and new ideas. He always gave me courage and hope to go on ${ }^{327}$... [he] has been so to speak a part of my own life ${ }^{328}$... I seem now quite dazed ... [and] wholly without energy to start the term. ${ }^{329}$ A chapter in the stormy history of genetics was closed.

\section{EPILOGUE}

Apart altogether from the impact of personal grief, Weldon's death, at the very time when the current of scientific opinion was moving strongly in favour of the Mendelians, was crucial. It removed the most committed ancestrian who had also been Bateson's main target. Bateson's animosity to Pearson, though never reaching the hostility he showed to Weldon, remained unabated; $;^{330}$ but with the air cleared of much of the personal acrimony the scientific values could now be judged more clearly. Earlier polarization of thinking was weakening and allowing intramural dissent. Bateson and Pearson became increasingly isolated one from the other: Pearson increasingly 'biometric'; Bateson stoutly 'biological', and neither without challenge from members of their own school. Weldon, the biologist turned biometrician, had been a link; now he was gone they went their own way. It was perhaps natural that on the death of one who was almost part of him Pearson should turn increasingly 
to other applications of their joint discoveries and of the methods they had developed together. These were mainly in the field of eugenics. Already a gift from Galton had established the Eugenics Record Office (in 1904) with staff in post and Pearson was to become increasingly involved with its affairs as the years went on.

The foundations for synthesis of ideas had been well laid by 1906 and by the start of the next decade the various branches of genetics advanced more or less together: that Pearson and Bateson no longer led reflects the shift in growth to other fields and in a sense also their increasing entrenchment. ${ }^{331}$ They had fed on their controversies in different ways. To Bateson preaching Mendelism was a mission-in the event a sacrificial one-but perhaps it was the only cause for which he would have sacrificed so deeply. To Pearson the debate on heredity was only one, though the greatest one, of the intellectual 'frays' ${ }^{\prime 32}$ which his temperament demanded: intellectual activity was his main dynamic; intellectual controversy had become his main outlet for emotion. Moreover he was becoming estranged from the scientific field of inheritance: he had neither the time nor training to remain central to a subject relying increasingly on biological findings for its development. Probably he had not the inclination either. As Professor E. S. Pearson has written: 'In the growing complexity of the Mendelian hypothesis, demanding more than ever in his [Karl Pearson's] view a stringent statistical examination of the inferences that were logically justifiable, he could not see those simple descriptive formulae which held so important a place in his conception of scientific law. And so he stood aloof, sceptical and often critical. ${ }^{, 333}$ But he still applied his formidable intellect and energy to heredity even if now bereft of some of the explorer's zeal, and for the rest of his life his work and authority contributed to the whole subject. ${ }^{334}$ Whether he ever came unequivocably to accept Mendelism, or whether indeed Bateson ever really accepted the conclusions flowing from the great cytological discoveries in the field, are subjects for another study.

\section{Summary}

This paper describes the formulation (by Francis Galton) and the development (by Galton and Karl Pearson) of the 'law of ancestral heredity' and the bitter controversies which surrounded it especially after the 'rediscovery' of Mendel's work in 1900.

The 'law' attempted to express quantitively commonplace observations about heredity which Darwin's theory of natural selection had left untouched; namely, that offspring resemble their parents and their sibs though not completely, that offspring of exceptional parents are usually less exceptional, and that characteristics are sometimes atavistic. It was consonant with physiological views of heredity.

After the 'rediscovery' and coeval discoveries in cytology the physiological underpinning of the law weakened. Two rival schools evolved: the Mendelians-led by William Bateson; and the 'ancestrians'-led by Pearson and Raphael Weldon. They engaged in much sterile and acrimonious argument, which on balance was harmful for human genetics, before their views were generally reconciled.

The article finishes with Weldon's death in 1906.

\section{Notes and Bibliography}

The following abbreviations are used:

K.P.

E.S.P. Pearson, E. S. (1936). Karl Pearson: An

Pearson, K. (1906-7). Walter Frank Raphael Weldon, 1860-1906. Biometrika, 5, 1-52. appreciation of some aspects of his life and work. Part I: 1857-1906. Biometrika, 28, 193-257.

Life Pearson, K. (1914-1930). The Life, Letters and Labours of Francis Galton. The University Press, Cambridge. Vol. I (1914); Vol. II (1924); Vols. IIIA, B (1930).

DNB Dictionary of National Biography. Edited

S. Lee. Smith, Elder, London, 1885-1900. Bateson, B. (1928). William Bateson, F.R.S. Naturalist. His Essays and Addresses together with a Short Account of his Life. The University Press, Cambridge.

Phil. Trans. Philosophical Transactions of the Royal Society of London.

Proc. Roy. Soc. Proceedings of the Royal Society of London.

When quoting correspondence, W. B. is William Bateson, F. G. is Francis Galton, K. P. is Karl Pearson, W. F. R. W. is Raphael Weldon. When citing from longer articles and books the precise pagination is given. $B i b$. refers to another item in the bibliography, e.g. Bib. 48 to item 48 .

1. Pearson's works, annotated and cross-indexed, have been gathered by Morant, G. M. (1939). A Bibliography of the Statistical and Other Writings of Karl Pearson. The University Press, Cambridge. It is out of print.

2. Pearson's writings on 'logical positivism' attracted the attention of Lenin who described him as 'this conscientious and scrupulous foe of materialism' (Haldane, J. B. S. (1957). Karl Pearson. Biometrika, 44, 303-313).

3. Bib. 1, items 407 to 410 .

4. Filon, L. N. G. (1936). Karl Pearson as an applied mathematician. Obituary Notices of Fellows of the Royal Society, 2, 104-110.

5. Clifford, W. K. (1885). The Common Sense of the Exact Sciences. Completed by Karl Pearson. Kegan Paul, Trench, London.

6. Todhunter, I. (1886-1893). A History of the Theory of Elasticity and of the Strength of Materials, from Galilei to the Present Time. Edited and completed by Karl Pearson, 2 vols. The University Press, Cambridge. 
7. Pearson, E. S. (1965). Studies in the history of probability and statistics. XIV: Some incidents in the early history of biometry and statistics. Biometrika, 52, 3-18.

8. E.S.P., pp. 207-210.

9. Pearson, K. (1880). The New Werther. Kegan Paul, London.

10. -(1882). The Trinity: A Nineteenth Century Passion-Play. The Son; or, Victory of Love. E. Johnson, Cambridge. This was written anonymously.

11. (1888). The Ethic of Freethought: A Selection of Essays and Lectures. T. Fisher Unwin, London.

12. -(1892). The Grammar of Science. Walter Scott, London. The title page quotation is 'La critique est la vie de la science', an apt motto for Pearson's philosophy.

13. In Berlin during $1879-80$ Pearson attended the lectures of Du Bois Reymond on Darwinism and in the first (1892) edition of The Grammar of Science quotes works of Huxley, Weismann, Darwin, Haeckel, Spencer, Nägeli, and others. Galton had influenced Pearson from as early as 1877 (Life, I, p. 2) especially in Pearson's 'view of mechanism .... conceived as applying to life rather than of dealing with the elementary principles of biology' (Bib. 12, p. 392). Pearson did not give his first lecture on inheritance until 11 March 1889 (K.P., p. $16 \mathrm{ft}$.) and this only to a private discussion club (Bib. 7, p. $4 \mathrm{ft}$.). This was after the publication of Galton's Natural Inheritance (Bib. 14). See also Life, IIIA, pp. 58 seq., $61 \mathrm{ft}$.

14. Galton, F. (1889). Natural Inheritance. Macmillan, London.

15. Life, IIIA, p. 57.

16. Ibid, p. 58 .

17. Speeches delivered at a Dinner held in University College, London, in Honour of Professor Karl Pearson, 23 April 1934, p. 22. The University Press, Cambridge, 1934.

18. K.P., p. 18.

19. Walter Weldon invented the 'Weldon process' for regenerating the manganese dioxide used in the manufacture of chlorine. Raphael's inheritance gave him an independence shared by Darwin and Galton but which Pearson and, in his early days, Bateson lacked. Raphael's widow in turn inherited this fortune and at her death, in 1936, left $£ 68,453$ despite previous gifts to the Ashmolean of paintings by Blake, Claude, Veronese, Corot, and Sisley. Much of this estate was bequeathed to endow a Chair of Biometry at University College, London, and in 1937 J. B. S. Haldane became the first occupant. (DNB, vol. 60, pp. 164-165; and Crowther, J. G. (1952). British Scientists of the Twentieth Century, p. 280. Routledge and Kegan Paul, London.) Galton was able to bequeath $£ 45,000$ to found a Chair of Eugenics at UCL (DNB (Second Supplement), vol. 2, pp. 70-73).

20. Details from K.P., passim; and DNB (Second Supplement), vol. 3, pp. 629-631.

21. Editorial (1901). Biometrika, 1, 1-6. The first part (pp. 1-2) was written by Weldon (K.P., Bibliography).

22. K.P., p. 9.

23. Ibid., p. 10.

24. Galton, F. (1869). Hereditary Genius, pp. vi, 33. Macmillan, London.

25. - (1885). Regression towards mediocrity in hereditary stature. Fournal of the Anthropological Institute of Great Britain and Ireland, 15, 246-263. This was Galton's Presidential Address.

26. (1886). Family likeness in stature. Proc. Roy. Soc., 40, 42-69.

27. (1888). Co-relations and their measurement, chiefly from anthropometric data. Ibid., 45, 135-145. The spelling of 'correlation' was not uniform at this time: 'correlation' became the accepted form only from 1889 (Life, IIIA, p. 57 ft.).

28. Weldon, W. F. R. (1890). The variations occurring in certain Decapod Crustacea. I: Crangon vulgaris. Ibid., 47, 445-453.

29. - (1892). Certain correlated variations in Crangon vulgaris. Ibid., 51, 2-21.

30. Galton helped Weldon with the analyses because Weldon showed a 'defect in mathematical grasp'. He was later to remedy this (K.P., p. 17).

31. W. F. R. W. to F. G. of 14 May 1890 and 29 Oct. 1891 (Life IIIB, pp. 483-484). Even at this time Galton seems to have placed a reciprocal confidence in Weldon since he sent him, in 1890, his MS 'Sexual generation and cross-fertilisation'. Weldon, however, commented unfavourably! (Life, IIIA, p. $318 \mathrm{ft}$.).

32. K.P., p. 16.

33. Gresham College was founded in 1597 with a bequest from the Tudor merchant and financier Sir Thomas Gresham. It was organized on medieval lines with a professor for each of divinity, astronomy, geometry, music, law, physic and rhetoric. By 1890 the professorial duties were to give annually three short courses of public evening lectures. Pearson's audience was mainly 'clerks and others engaged during the day in the City' (E.S.P., p. 213) and his lectures planned accordingly. (See his Probationary Lecture delivered on 12 December 1890: Pearson, K. (1891). The applications of geometry to practical life. Nature, London, 43, 273276).

34. Yule, G. U. (1936). Karl Pearson 1857-1936. Obituary Notices of Fellows of the Royal Society, 2, 73-104.

35. (1897). Note on the teaching of the theory of statistics at University College. Fournal of the Royal Statistical Society, 60, 456-458.

36. For these syllabuses see: Pearson, E. S. (1938). Karl Pearson: An Appreciation of some Aspects of his Life and Work, Appendix I and II. The University Press, Cambridge. Syllabuses for the first seven (MarchApril, 1891) are also in E.S.P., Appendix I.

37. Pearson resigned in May 1894 because of pressure of work (E.S.P., p. 216).

38. The last lecture, on death rates, provided substance for a book (Pearson, K. (1897). The Chances of Death and other Studies in Evolution. Edward Arnold, London).

39. Weldon, W. F. R. (1893). On certain correlated variations in Carcinus moenas. Proc. Roy. Soc., 54, 318-329.

40. W.F.R.W. to F.G. of 27 Nov. 1892 (Bib. 7, p. 8 ft.).

41. W.F.R.W. to K.P. of 27 Nov. 1892 (Bib. 7, p. 8).

42. Pearson, K. (1894). Contributions to the mathematical theory of evolution. Phil. Trans., A185, 71-110.

43. The first two in the numbered series (Bib. 42 and 147) had the word 'mathematical' placed before 'theory': the others (III to XIX) had 'mathematical' before 'contributions'. In addition there were eight unnumbered publications under the latter title.

44. Galton expounded the principles but it was Pearson (in 1898) who coined the term $(B i b .87)$ and its variant 'the law of ancestral inheritance' (Life, IIIA, p. 21). The 'law' is not, of course, a biological hypothesis but simply the mathematical expression of statistical variates.

45. Undated MS (Life, II, p. 70).

46. Life, II, p. 70.

47. Galton, F. (1865). Hereditary talent and character. Macmillan's Magazine, 12, 157-166, 318-327. 
48. This was Pearson's view (Life, II, p. 84). Galton later seemingly (Bib. 24, p. $372 \mathrm{ft}$.) then tacitly corrected it (Bib. 25).

49. Darwin, C. (1868). The Variation of Animals and Plants under Domestication, ch. 27. 2 vols. Murray, London.

50. Olby, R. C. (1963). Charles Darwin's manuscript of Pangenesis. British fournal of the History of Science, 1, 251-263.

51. Swinburne, R. G. (1965). Galton's law-formulation and development. Annals of Science, 21, 15-31. Darwin and Galton were half-cousins (their common grandparent was Erasmus Darwin) and were frequently in communication. There is no evidence, however, that Galton had any prescience of Darwin's 'pangenesis' theory though he would have known some of its precursors.

52. Vorzimmer, P. (1963). Charles Darwin and blending inheritance. Isis, 54, 371-390; Olby, R. C. (1965). The Mendel Centenary. British fournal of the History of Science, 2, 343-349.

53. Bib. 24, pp. 363 seq.

54. Galton, F. (1908). Memories of my Life, p. 309. Methuen, London.

55. Galton's theory of 'stirp' is very similar to Weismann's 'germplasm' (page 16): in fact the latter felt obliged to devote two pages of his book to trying unsuccessfully to assert his prior statement of the general hypothesis (Weismann, A. (1893). The Germ Plasm. A Theory of Heredity. Translated by $W$. Newton Parker and Harriet Rönnfeldt, pp. 198-200. Scott, London). Galton, though he dissented, was too courteous to engage in public dispute.

56. Galton, F. (1877). Typical laws of heredity. Cited in Life, IIIA, pp. 6 seq.

57. $B i b .25,26$. See also Life, IIIA, ch. 14, for other references.

58. Galton, F. (1886). Family likeness in eye colour. Proc. Roy. Soc., 50, 402-416.

59. Life, II, pp. 357 seq.

60. Galton, F. (1884). Record of Family Faculties. Macmillan, London.

61. Edited Galton, F. (1884). Life History Album. Prepared by direction of the Collective Investigation Committee of the British Medical Association. Macmillan, London.

62. Galton, F. (1897). The average contribution of each several ancestor to the total heritage of the offspring. Proc. Roy. Soc., 61, 401-413.

63. Life, IIIA, pp. 11 seq. Initially (Bib. 56) Galton called this phenomenon 'reversion'. Later, when he reached the correlation coefficient as a special case of regression he symbolized it as $r$-the first letter of 'reversion' and only incidently also of 'regression'-and this is now the universal symbol for the sample correlation coefficient.

64. Bib. 14, p. 97. Galton throughout accepted linearity and homoscedasticity which was reasonable on his data.

65. This was derived from his 'special data' and related only to males (783 brothers in 295 families). Pearson considered this group heterogeneous since it contained members of an Essex volunteer regiment: later, when he omitted the regiment members and pooled the remainder with the R.F.F. males, he reached an unweighted mean 'fraternal' regression coefficient of 0.5013 , i.e. approximating the theoretical sib/sib expectation (Life, IIIA, p. 25).

66. Life, IIIA, pp. 22 seq.

67. Bib. 14, pp. 134 seq.

68. Ibid., pp. 134-135.
69. Life, IIIA, p. 23.

70. Bib. 58. Inheritance of eye-colour had been previously studied only by Alphonse de Candolle (de Candolle, A. P. (1884). Hérédité de la couleur des yeux dans l'espèce humaine. Archives des sciences physiques et naturelles, 12, 97-120) but with imperfect data and analytical method (Life, IIIA, p. 34). De Candolle had previously criticized (de Candolle, A. P. (1873). Histoire des Sciences et des Savants depuis Deux Siècles: Suivie d'autres études sur des sujets scientifiques en particulier sur la sélection dans l'espèce humaine. Genèva) and Galton had spiritedly defended (Galton, F. (1874). English Men of Science, their Nature and Nurture. Macmillan, London), the emphasis on inheritance in Hereditary Genius (see Life, II, pp. 145 seq.), but nevertheless they corresponded amicably until at least 1890 (Life, II, pp. 131-149, 204-210; IIIB, pp. 474, 476$481,483)$.

71. Life, IIIA, p. 39. The invalidities in the method are detailed by Pearson (Life, IIIA, pp. 34-40).

72. Ibid., pp. 45-50.

73. Bib. 54, p. 308.

74. Galton, F. (1897). A new law of heredity. Nature, London, 56, 235-237.

75. About this time Pearson wrote: ‘ $\ldots$. with all due reservations, it seems to me that the law of ancestral heredity ... is highly probably .... the simple descriptive statement which bring into a single focus all the complex lines of hereditary influence' (Bib. 87). Over thirty years later he was more guarded but was still a convinced adherent: 'In [my] opinion the Law of Ancestral Heredity has been shown by Galton to be at least approximate in two very different cases and this justifies further attempts to deal with it ... '(Life, IIIA, p. 44). Both Galton and Pearson retained their belief in the ancestral law long after the 'rediscovery'.

76. Galton, F. (1897). Hereditary colour in horses. Nature, London, 56, 598-599.

77. (1897). Rate of racial change that accompanies different degrees of severity in selection. Ibid., 55, 605 .

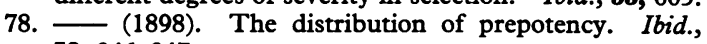
$58,246-247$.

79. Life, IIIA, p. 21. Pearson considers this was also Galton's view (Ibid., p. 60).

80. Pearson, K. (1896). Mathematical contributions to the theory of evolution-III. Regression, heredity, and panmixia. Phil. Trans., A187, 253-318.

81. Bravais (Bravais, A. (1846). Sur les probabilités des erreurs de situation d'un point. Mémoires de l'Académie Royale des sciences de l'Institut de France, 9, 255-332) is often credited with being the first to give the theories of correlation and to reach the expression, later to be termed the 'Galton function' (coefficient of correlation), though unlike Galton he did not use a single symbol for it. This view is incorrect (Pearson, K. (1920). Notes on the history of correlation. Biometrika, 13, 25-45). Others especially Edgeworth (Edgeworth, F. Y. (1892). Correlated averages. Philosphical Magazine, 34, 190204), extended some of the early theory. Early European work is reviewed by Seal, H. L. (1967). Studies in the history of probability and statistics. XV: The historical development of the Gauss linear model. Biometrika, 54, 1-24.

82. Yule, G. U. (1897). On the significance of Bravais' formulae for regression, etc., in the case of skew correlation. Proc. Roy. Soc., 60, 477-489.

83. (1897). On the theory of correlation. Fournal of the Royal Statistical Society, 60, 812-854. Yule termed 
partial correlation 'net correlation', Pearson later recommending the former term (Bib. 34, p. $82 \mathrm{ft}$.).

84. Galton failed to grasp the concept of multiple regression and adduced the ancestral law ambiguously in Natural Inheritance in 1889 (Bib. 14, pp. 132-135), Pearson supposing him to mean that 'the coefficients of correlation between offspring and parent, grandparent, greatgrandparent etc., were to be taken as $r, r^{2}, r^{3}$ etc.' (Bib. 87). If this were so the ancestral multiple regression would reduce to a simple biparental regression, higherorder coefficients being zero (Life, IIIA, p. $39 \mathrm{ft}$.). Galton's 1897 formulation (Bib. 62) was more precise and, after reciprocal correspondence, Pearson brought the strands together in 1898 (Bib. 87).

85. Bib. 80 , p. 306 .

86. Pearson, K. and Lee, A. (1896). Mathematical contributions to the theory of evolution. On telegony in man. Proc. Roy. Soc., 60, 273-283. Telegony describes the phenomenon where a female mating with a male bears to him offspring resembling in some way a previous mate. The importance of such a phenomenon to contemporary physiological explanations of heredity is clear. The example cited for man is a pedigree by Lingard (Lingard, A. (1884). The hereditary transmission of hypospadias and its transmission by indirect atavism. Lancet, 1, 703; also noted in Sedgwick, W. (1896). Notes on the influence of heredity in disease. British Medical fournal, $1,458-462$ ) where a woman bore a hypospadic man three hypospadic sons and another normal man four hypospadic sons.

87. Pearson, K. (1898). Mathematical contributions to the theory of evolution. On the law of ancestral heredity. Proc. Roy. Soc., 62, 386-412. In the following paper Pearson further tested the law using the cephalic index from Dr. Franz Boas' data on North American Indian skulls (Fawcett, C. D. and Pearson, K. (1898). Mathematical contributions to the theory of evolution. On the inheritance of the cephalic index. Ibid., 413-417).

88. Galton commented: 'It delights me beyond measure to find that you are harmonising what seemed disjointed and cutting out and replacing the rotten planks of my propositions' (F.G. to K.P. of 4 Jan. 1898, in Life, IIIB, p. 504).

89. Quotation from Bib. 11 and cited in E.S.P., p. 203.

90. The ancestral law was not based on any clear conception of a mechanism of heredity and by using or condoning terms of no strict physical meaning or biological rationale e.g. 'contributions to a heritage', 'taxation of the inheritance', 'taxation of the ancestral contributions', Galton and Pearson alienated their ideas from many biologists. Furthermore, their method of presentation often gave the erroneous impression, to those unused to interpreting in terms of regression, that the law was applicable to the individual case or mating.

91. Pearson, K. and Lee, A. (1900). Mathematical contributions to the theory of evolution. VIII: On the inheritance of characters not capable of exact quantitative measurement. Part I, Introductory; Part II, On the Inheritance of coat colour in horses; Part III, On the Inheritance of eye colour in man. Phil. Trans., A195, 79-150. See also Life, IIIA, pp. 34 seq.

92. Pearson, K. (1900). Mathematical contributions to the theory of evolution. VII : On the correlation of characters not quantitatively measurable. Phil. Trans., A195, 1-47. 'Tetrachoric $\mathbf{r}$ ' has had a chequered history. Yule, in developing his 'coefficient of association' for a $2 \times 2$ contingency table, had suggested the possibility of regarding such a table as a double dichotomy of a bivariate normal surface (Yule, G. U. (1900). On the association of attributes in statistics. Ibid., A194, 257-319.) On these very limiting assumptions 'tetrachoric $r$ ' was devised by Pearson but then applied invalidly to such double dichotomies as 'vaccinated-not vaccinated', 'died-recovered'. A long controversy finished with Pearson defending 'tetrachoric $r$ ' in an acrimonious 156-page article (Pearson, K. and Heron, D. (1913). On theories of association. Biometrika, 9, 159-315) later described by Kendall (Kendall, M. G. (1943). Advanced Theory of Statistics, vol. I, p. 322. C. Griffin, London) as 'remarkable for having missed the point over more pages than perhaps any other memoir in statistical history'.

93. - (1900). Mathematical contributions of the theory of evolution. On the law of reversion. Proc. Roy. Soc., 66, 140-164. This was sub-headed 'A New Year's greeting to Francis Galton-January 1st, 1900'.

94. A third type of heredity-'mosaic' inheritance, viz. part of the offspring resembling one parent and the rest the other-was also recognized.

95. Pearson, K. (1900). The Grammar of Science, 2nd ed., pp. 494-495. A. \& C. Black, London.

96. E.g. Bib. 95, p. 480 . Pearson was always groping towards some simple universal law which would explain evolution and heredity.

97. Bib. 91, p. 121.

98. Pearson's three atricles (Bib. 91 to 93 ) originally comprised a single paper submitted to the Royal Society on 5 August 1899 and 'read' on 16 November. Pearson had it returned for corrections and with some expansion resubmitted the work between January and March 1900 as the three papers described here (Bib. 91, p. 80 ; and $B i b$. 92, p. 1).

99. W.F.R.W. to F.G. of 4 Dec. 1893 (Life, IIIA, p. 290). This meeting was held at the Savile Club on 9 December 1893 (K.P., p. 23).

100. Members were to be Francis Darwin, Galton, A. Macalister, R. Meldola, E. P. Poulton and Weldon, and the petition stated that it may afterwards be desirable to add a statistician' (K.P., p. 23).

101. Facts from: Life, IIIA, p. 126; K.P., p. 23; and F.G. to K.P. of 16 July 1906, in Life, IIIA, pp. 290-291. Galton, following an idea put to him by Alfred Russel Wallace (A.R.W. to F.G. of 3 Feb. 1891, in Life, IIIA, pp. 128-129), had in 1892 first suggested an 'institute for experiments on heredity' (Bib. 122, p. xix), and the Royal Society committee and the later (1896) abortive movement to establish a biological farm on Charles Darwin's former property at Down in Kent (Life, IIIA, pp. $133 \mathrm{seq}$.) both stemmed from this. Meldola preempted the future biometricians by referring, in December 1896, to the biological farm as a 'biometric station' (Life, IIIA, p. $133 \mathrm{ft}$.).

102. K.P., p. 24.

103. Weldon, W. F. R. (1895). Report of the committee ... for conducting statistical enquiries into the measurable characteristics of plants and animals. Part I : An attempt to measure the death-rate due to the selective destruction of Carcinus moenas with respect to a particular dimension. Proc. Roy. Soc., 57, 360-379.

104. - (1895). Ibid. Part II : Remarks on variation in animals and plants. Ibid, 379-382. This, and Bib. 103, though technically committee publications, were written by Weldon on his own results.

105. K.P., p. 25.

106. K.P., p. $26 \mathrm{ft}$.

107. There were many shades of opinion within the ranks of 
biologists and naturalists which cannot be traced here. Most opposed Weldon though mainly because they either disagreed with his methods or did not understand them. Only Bateson's small school opposed his evolutionary ideas. Bateson's own theories were at this time unpopular. See also Bib. 193.

108. Bateson wrote to his wife, the day after Weldon died: 'Until the time-about 16 years ago [1890]-when his mind began to embitter itself against me, I was more intimate with him than I have ever been with anyone but you' (W.B. to B.B. of 16 April 1906, in B.B., p. 102). Pearson dated the start of their enmity more exactly: 'Bateson's attacks did not start until Weldon had reviewed [his] book [Bib. 110] in $1894 \ldots$ and then they became incessant and ceased only with the death of Weldon' (K.P. to F.G. of 11 July 1906, in Life, IIIA, pp. 287-288).

109. Weldon, W. F. R. (1894). The study of animal variation. Review of Materials for the Study of Variation, Etc., by W. Bateson. Nature, London, 50, 25-26.

110. Bateson, W. (1894). Materials for the Study of Variation treated with especial Regard to Discontinuity in the Origin of Species. Macmillan, London.

111. Weldon, W. F. R. (1895). Origin of the cultivated Cineraria. Nature, London, 52, 54.

112. Botting, W. H. (1895). Ibid., 54-55.

113. Thistleton-Dyer, W. T. (1895). Variation and specific stability. Ibid., 51, 459-461.

114. (1895). Origin of the cultivated Cineraria. Ibid., 52, 3-4, 78-79, 128-129.

115. Bateson, W. (1895). Ibid., 51, 605-607; 52, 29, 103104.

116. - (1897). Notes on hybrid Cinerarias produced by Mr Lynch and Miss Pertz. Proceedings of the Cambridge Philosophical Society. Mathematical and Physical Sciences, 9, 308-309.

117. The orthodox view was that cultivated forms of Cineraria came from a wild species through the gradual accumulation of small variations induced by the horticulturist. Bateson, on the other hand, held that they had come through hybridization between several recognized species, and this led to his extensive breeding experiments reported in the first four Reports to the Evolution Committee of the Royal Society, 1902-1908 (Bib. 198 to 201).

118. K.P., p. 26.

119. Life, IIIA, p. $127 \mathrm{ft}$

120. Life, IIIA, p. 127.

121. K.P. to F.G. of 14 July 1906 (Life, IIIA, pp. 289-290).

122. E.g. Galton, F. (1892). Hereditary Genius: An Enquiry into its Laws and Consequences, 2 nd ed., pp. xviii-xix. Macmillan, London. Pearson characteristically defended what he considered to be Galton's heresy and (much later) wrote: 'it is quite certain that Galton in 1892 supported evolution by mutations owing to an error in interpretation [in regression in his "ancestral law']' (Life, IIIA, p. 80). (Our italics.)

123. (1894). Discontinuity in evolution. Mind, $\mathbf{3}$ 362-372.

124. Life, IIIA, p. 126. This was the statistician the petittioners had foreseen (Bib. 100).

125. F.G. to W.F.R.W. of 17 Nov. 1896 (Life, IIIA, p. 127)

126. E.g., F.G. to K.P. of 15 Feb. 1897 (Life, IIIB, p. 501).

127. From entries in his own diary and the committee minute book, Galton concluded that Bateson attended meetings of the committee in January (when he was elected) and on 26 February 1897 (F.G. to K.P. of 16 July 1906, in Life, IIIA, pp. 290-291). Beatrice Bateson, however, says that her husband refused the initial invitation 'early in 1897' and suggests that he did not join the committee after it was re-constituted later in the year (B.B., p. 60).

128. Life, IIIA, p. 127

129. Life, IIIA, p. $128 \mathrm{ft}$. The name and constitution of the enlarged committee were chosen by Galton partly to further his abortive 'biological farm' idea (Life, IIIA, p. 128).

130. Bib. 121. Following a suggestion by Meldola, Galton flirted with the title 'Phylometric Committee' seemingly as late as the week before the term 'Evolution Committee' was proposed (F.G. to R. Meldola of 7 Dec. 1896, in Life, IIIB, pp. 500-501).

131. Though only 43 this was probably the last scientific committee on which Pearson served (Bib. 34, p. 100). From 1895 to 1899 he was also a member of a statistical committee of the British Association (Bib. 1, items 9 and 25). There is no doubt that even then Pearson sensed that failure of communication with traditional biologists which accentuated their differences in outlook: 'I felt sadly out of place in such a gathering of biologists, and little capable of expressing opinions which would only have hurt their feelings ... I always succeed in creating hostility without getting others to see my views....!' (K.P. to F.G. of 12 Feb. 1897, in Life, IIIA, pp. 127128.)

132. K.P. to F.G. of 28 June 1906 (Life, IIIA, pp. 285-286). See also Life, IIIA, p. 127; and F.G. to K.P. of 16 July 1906 (Life, IIIA, p. 291). As early as 15 June 1899, and again on 29 November, the committee under Galton had debated whether or not it should remain in existence.

133. Weldon, W. F. R. (1897). Report to the Evolution Committee on the Growth of Carcinus moenas at successive Moults. Unpublished. (K.P., p. 26.)

134. - (1898). Presidential Address to Section D-Zoology (including Animal Physiology) - of the British Association. Report of the British Association for the Advancement of Science, pp. 887-902. This was given at Bristol on 8 September 1898.

135. Much of Weldon's crab work on natural selection was later strongly criticized. (Fothergill, P. G. (1952). Historical Aspects of Organic Evolution, p. 377. Hollis and Carter, London.)

136. Darwin, C. (1859). The Origin of Species, ch. XV. John Murray, London.

137. Weldon corresponded ardently with Pearson often writing 'almost daily' in the early Oxford years (K.P., p. 33). His letters were usually long, often 'almost a treatise ... with long tables [compiled] with apparent ease and as a work of supererogation' (F.G. to K.P. of 7 May 1906, in Life, IIIA, p. 282). Most reciprocal correspondence is lost because Weldon systematically destroyed all letters he received, the few surviving being ones he had overlooked or mislaid (Life, IIIB, p. $542 \mathrm{ft}$.).

138. Life, IIIA, pp. 279 ft., $280 ;$ K.P., pp. 34, 40 seq.

139. Co-operative Study (1903). Assortative mating in man. Biometrika, 2, 481-498. This was written by Pearson and Weldon (K.P., p. 42). Pearson also grew poppies as part of the co-operative venture of Oliver, Tansley, Macdonnell, Weldon and himself (Co-operative Study (1902). Co-operative investigations in plants. I: On inheritance in the Shirley Poppy. Biometrika, 2, 56$100)$, though Weldon was the instigator and main contributor and author (K.P., p. 33; K.P. to W.F.R.W. of 23 April 1900, in page 162 of Pearson, E. S. (1938). Karl Pearson. An appreciation of some aspects of his life and work. Part II : 1906-1936. Biometrika, 29, 161-248). 
140. Pearson, K. (1904). Mathematical contributions to the theory of evolution. XII : On a generalised theory of alternative inheritance, with special reference to Mendel's laws. Phil. Trans., A203, 53-86. Weldon was collaborator but refused to accept joint authorship because 'he had taken no part in certain portions of the more complicated algebraic analyses' (K.P., p. 43).

141. - (1908). On a mathematical theory of determinantal inheritance from suggestions and notes of the late W. F. R. Weldon. Biometrika, 6, 80-93.

142. Miscellanea (1903). Inheritance in Phaseolus vulgaris. Biometrika, 2, 499-503. This was a joint critical review of Johannsen, F. (1903). Ueber Erblichkeit in Populationen und in reinen Linien. Fischer, Jena. This book was dedicated to Galton as the 'Founder of the science of the exact study of heredity'.

143. Two months after Weldon's death (in 1906) Pearson wrote to Galton: 'Our friendship [Weldon and Pearson] had gone through the fire and nothing can modify my judgement or affection now ... he has been so to speak a part of my own life' (K.P. to F.G. of June 1906, in Life, IIIA, p. 285).

144. Pearson, E. S., Bib. 139, p. 161.

145. Pearson, K. (1900). The Grammar of Science, 2nd ed. Macmillan, London.

146. E.S.P., p. 223.

147. Pearson, K. (1895). Contributions to the mathematical theory of evolution. II : Skew variation in homogeneous material. Phil. Trans., A186, 342-414.

148. Pearson was not led immediately to the study of skewness by Weldon but by F. Y. Edgeworth, though it was a logical step from the 'double humped' curve. Edgeworth consulted Pearson in the autumn of 1893 concerning methods to apply to skew curves of prices (Pearson had come briefly to skewness in his Gresham lectures), and 'I [Pearson] went to him in about a fortnight and said I have got a solution out, here is the equation ... I don't intend to publish till I have illustrated every point from practical statistics'. (K.P. to W. H. Macauley of 18 August 1895 , in Bib. 7, p. 10.)

149. W.F.R.W. to K.P. of 23 April 1893 (Bib. 7, p. 9). As a disciple of Galton, Weldon had initially supposed that biological measurements would be symmetrical within a homogeneous race, but he was prepared to re-think his views if they were not.

150. Bib. 1, items 9, 34, 240.

151. E.g. his Type III curve has been extensively used as the theoretical model for 'liability' on which the important epidemiological hypothesis of 'proneness', e.g. accidentproneness, sickness-proneness, has been constructed. (E.g. Froggatt, P. (1970). Application of discrete distribution theory to the study of non-communicable events in medical epidemiology. In Random Counts in Scientific Work: Vol. 2. Random Counts in Biomedical and Social Sciences, pp. 15-40. Edited G. P. Patil. Pennsylvania State University Press.)

152. For summary see: Froggatt, P. (1970). Modern Epidemiology: The Pearsonian Legacy. Inaugural Lecture, The Queen's University, Belfast ; and Pearson, E. S. (1967). Studies in the history of probability and statistics. XVII: Some reflexions on continuity in the development of mathematical statistics, 1885-1920. Biometrika, 54, 341-355.

153. Bib. 147, p. 411 . See also Bib. 64.

154. Pearson, K. and Lee, A. (1897). Mathematical contributions to the theory of evolution. On the relative variation and correlation in civilised and uncivilised races. Proc. Roy. Soc., 61, 343-357.
155. - and Filon, L. N. G. (1898). Ibid. IV: On the probable errors of frequency constants and on the influence of random selection on variation and correlation. Phil. Trans., A191, 229-311. Filon was Pearson's demonstrator and later succeeded him to the Goldsmid Chair. Fisher (Fisher, R. A. (1922). On the mathematical foundations of theoretical statistics. Phil. Trans., A222, 309-368) later commented on this article and Pearson's last word (Pearson, K. (1936). Method of moments and method of maximum-likelihood (with note and appendices). Biometrika, 28, 34-59), in which he defended fitting curves by moments as against maximum-likelihood, was published posthumously.

156. Pearson, K. (1900). On the criterion that a given system of deviations from the probable in the case of a correlated system of variables is such that it can be reasonably supposed to have arisen from random sampling. Philosophical Magazine, 50, 157-175. Ironically, Pearson never fully accepted what was to become the standard method of calculating the appropriate number of degrees of freedom with $\chi^{2}$ : he generally advocated using the number of classes itself, e.g. four instead of one on a fourfold table. (E.g. Pearson, K. (1922). On the $\chi^{2}$-test of goodness of fit. Biometrika, 14, 186-191.) This paper, a strong attack on Fisher'Don Quixote tilting at windmills' - for a critical article (Fisher, R. A. (1922). The interpretation of $\chi^{2}$ from contingency tables and the calculation of $\mathbf{P}$. Fournal of the Royal Statistical Society, 85, 87-94) exemplifies the power of Pearson's polemic and his inability to sympathize with any view he did not himself hold. He remained unrepentent until the end (e.g. Pearson, K. (1932). Experimental discussion of the $\left(\chi^{2}, \mathrm{P}\right)$ test for goodness of fit. Biometrika, 24, 351-381.) Historically the distribution Pearson symbolized as $\chi^{2}$ was reached by Abbe in 1863 and the astronomer Helmhert in 1876 but under different circumstances. (Sheynin, O. B. (1966). Origin of the theory of errors. Nature, London, 211, 1003-1004.)

157. Bib. 80 , p. 258.

158. Pearson, K. (1896). Contributions to the mathematical theory of evolution. Note on reproductive selection. Proc. Roy. Soc., 59, 301-305.

159. - Lee, A., and Bramley-Moore, L. (1899). Mathematical contributions to the theory of evolution. VI: Genetic (reproductive) selection: Inheritance of fertility in man, and of fecundity in thoroughbred race-horses. Phil. Trans., A192, 257-330. Pearson's use of the term 'reproductive selection' had been criticised after his preliminary paper (Bib. 158), but he always retained it. Galton, however, as a referee for the present paper, suggested several alternatives and from these Pearson, in deference, accepted 'genetic selection', and this appears as an alternative in both title and text. (K.P. to F.G. of November and December 1898, in Life, IIIB, pp. 505 seq.)

160. Beeton, M. and Pearson, K. (1899). Data for the problem of evolution in man. II : A first study of the inheritance of longevity and the selective death-rate in man. Proc. Roy. Soc., 65, 290-305. Between 27 April 1899 and 14 June 1900 Pearson and his colleagues read five papers (I to V) to the Royal Society under the heading 'Data for the problem of evolution in man', each published in the Proceedings. After the foundation of Biometrika (in 1901) papers under this general heading from other authors were accepted for that journal, but Pearson, as editor, chose the title himself. E.g. Powys, A. O. (1901). Data for the problem of evolution in man. 
Anthropometric data from Australia. Biometrika, 1, 30-49.

161. The sources (Foster's Peerage and Burke's Landed Gentry) were complete only for adult males. Fuller family records from the Society of Friends were later used, the general conclusion then drawn-Natural selection is manifestly at work in man [as regards longevity] and is a factor in 50 to 80 per cent of the deaths which occur'-being similar (Beeton, $M$. and Pearson, $K$. (1901). Inheritance of the duration of life and the intensity of natural selection in man. Biometrika, 1, 5089).

162. Pearson used this term to describe that category of assortative mating where there is a positive correlation between the same characteristics in spouses.

163. Pearson, K. (1899). Data for the problem of evolution in man. III: On the magnitude of certain coefficients of correlation in man. Proc. Roy. Soc., 66, 23-32. The factors correlated are: birth frequency and lunar phase (zero), birth-weight and birth-length $(\bumpeq 0.60)$; height, weight, 'strength of pull' and head index (zero-order values) and fertility and homogamy.

164. - (1900). Data for the problem of evolution in man. IV: Note on the effect of fertility depending on homogamy. Ibid., 66, 316-323.

165. Beeton, M., Yule, G. U., and Pearson, K. (1901). Data for the problem of evolution in man. V: On the correlation between duration of life and number of offspring. Ibid., 67, 159-179. The data used were from records of English and American Quakers and from Burke's Landed Gentry. See also Bib. 145, pp. 448-449.

166. Pearson, K. (1898). Mathematical contributions to the theory of evolution. V: On the reconstruction of the stature of prehistoric races. Phil. Trans., A192, 169244.

167. Whiteley, M. A. and Pearson, K. (1899). Data for the problem of evolution in man. I: A first study of the variability and correlation of the hand. Proc. Roy. Soc., 65, 126-151. This is the first paper (of six) in this numbered series. It was continued as a 'second study' by Lewenz and Whiteley (Lewenz, M. A. and Whiteley, M. A. (1902). Data for the problem of evolution in man. A second study of the variability and correlation of the hand. Biometrika, 1, 345-360).

168. For reviews see $B i b .1,4,34$.

169. Pearson, K. (1892). The New University for London. $A$ Guide to its History and a Criticism of its Defects. T. Fisher Unwin, London.

170. Pearson also wrote or rewrote many papers on data collected by others and which were published in their names alone (Bib. 1, Foreword).

171. E.S.P., pp. 223-224.

172. K.P. to W.F.R.W. of 23 April 1900 (Pearson, E. S., Bib. 139, p. 162).

173. These included veins, pinnae, or prickles in certain tree leaves, 'gill-index' of the mushroom, and stigmatic bands on seed capsules of Shirley poppies-this last leading to and intraclass correlation table of nearly 200,000 entries!

174. Pearson, K., Lee, A., Warren, E., Fry, A., and Fawcett, C. D. (1901). Mathematical contributions to the theory of evolution. IX: On the principle of homotyposis and its relation to heredity, to the variability of the individual and to that of the race. Part I: Homotyposis in the vegetable kingdom. Phil. Trans., A197, 285-379. Part II-Homotyposis in the animal kingdom-was announced before 1912 but was never published (Pearson, K., Warren, E., Lee, A., Lea-Smith, E., and
Crawford, M., Mathematical Contributions to the (D) Theory of Evolution. XVII: On Homotyposis in the $\overrightarrow{\mathbb{D}}$ Animal Kingdom. Draper's Company Research Memoirs, Biometric Series V). Of Part I, Bateson wrote: 'It is impossible to write of Professor Pearson's paper without expressing a sense of the extraordinary effort which has gone to its production and of the ingenuity it displays' (Bib. 183).

175. Abstract of Bib. 174. Proc. Roy. Soc., 68, 1-5 (1900).

176. The length as well as the content seems also to have been an issue (K.P. to F.G. of 1 Feb. 1901, in Life, IIIA, p. 243). See also Bib. 185.

177. K.P. to F.G. of 13 Dec. 1900 (Life, IIIA, p. 241).

178. '.. if the R.S. people send my papers to Bateson, one cannot hope to get them printed. It is a practical notice to quit. This notice applies not only to $m y$ work, but to most work on similar statistical lines' (Ibid.).

179. K.P., p. 35.

180. K.P. to F.G. of 13 Dec. 1900 (Life, IIIA, p. 241) and F.G. to K.P. of 23 April 1901 (Ibid., pp. 244-245). For further correspondence on the foundation of Biometrika see Ibid., pp. 241 seq. Davenport, co-editor, later broke with Pearson, siding with Bateson's views on evolution, but he remained on the editorial staff of Biometrika until 1909. (For details and bibliography see Rosenberg, C. E. (1961). Charles Benedict Davenport and the beginning of human genetics. Bulletin of the History of Medicine, 35, 266-276.)

181. Pearson, Christened 'Carl', changed this spelling to 'Karl' during post-graduate study in Germany, 'which may have been homage to German culture or a special homage to Karl Marx' to whose teaching Pearson was attracted (Bib. 2). When he named Biometrika he preferred the Germanic ' $K$ ' to the English ' $C$ ': 'I gave the name-the ' $K$ ' was mine (K.P. not C.P.) . . '. This was allusion to his own initials (K.P. to F.G. of $13 \mathrm{Dec}$. 1900, in Life, IIIA, p. 241).

182. Quotation from Pearson, K. (1902). On the fundamental conceptions of biology. Biometrika, 1, 320-344.

183. Bateson, W. (1901). Heredity, differentiation, and other concepts of biology: A consideration of Professor Karl Pearson's paper 'On the principle of homotyposis' Proc. Roy. Soc., 69, 193-205. This paper concludes with a note, added in November 1901 after Pearson's full paper (Bib. 174) appeared, which deals with Pearson's attempt to answer certain comments of a referee, in fact Bateson himself. Bateson in this paper fights Pearson on the latter's home ground which may help to explain his moderacy of tone and the confidence with which Pearson answers him.

184. There is some doubt as to when this paper (Bib. 174) was finally accepted. In 1902 (Bib. 182, p. 337) Pearson said that his paper was accepted 'some weeks' after 14 February 1901-when Bateson's paper (Bib. 183) was 'read'; but in a letter to Galton dated 1 February 1901 he says 'You will share my pleasure in the acceptance of the Homotyposis paper for the Phil. Trans.' (K.P. to F.G. of 1 Feb. 1901, in Life, IIIA, pp. 243-244.) Bateson's criticisms are in fact put temperately-as against the acerbity of Pearson's rejoinder (Bib. 182)and in contrast to his attacks on Weldon (Bib. 259) about the same time. Characteristically, Pearson took up the general principle of ethics raised by Bateson's and Foster's procedure and after much effort and final appeal to the President, he gained his point (E.S.P., p. 231).

185. Life, IIIA, p. 100 . It must be said that the R. S. Committee of Papers had been troubled for several years by whether to classify Pearson's articles as 'mathematical' or 
'biological'. In June 1902 they passed a resolution enjoining the author, in mixed papers, to keep the material separate and the numerical application of theory to a minimum. Presentation in extenso of data and their analysis was to be a specific function of Biometrika (E.S.P., pp. 232-233 ft.). See also Bib. 176.

186. General facts about the origins of Biometrika from: K.P. pp. $34 \mathrm{seq}$; Life, IIIA, pp. $100 \mathrm{seq}$; and E.S.P. pp. 228232. The editors could of course reject submitted material. This was the fate of Bateson's reply to Pearson's rejoinder (Bib. 182) to the former's criticism (Bib. 183) of the homotyposis paper (Bib. 174) and Bateson finally had it printed privately (in July 1903) using the identical format of Biometrika! (Bateson, W. (1903). Variation and Differentiation in Parts and Brethren. Privately printed by the Cambridge University Press: reproduced in $B i b$. 212, vol. I, pp. 419-445). Punnett, Bateson's close colleague, concluded from this 'that the pages of Biometrika were also [with Nature] closed to him [Bateson]' (Bib. 206).

187. K.P., p. 36 . Pearson read Mendel about the same time and immediately tested the theory of dominance on his eye-colour data (Pearson, K., Bib. 273, p. $213 \mathrm{ft}$.).

188. Bateson read Mendel's paper on the train between Cambridge and London on his way to read a paper 'Problems of heredity as a subject for horticultural investigation' to the Royal Horticultural Society. The date was 8 May 1900 . He at once incorporated Mendel's 'principles' into his lecture and in more detail in the published article (Bib. 195). He learned of Mendel's work from de Vries' (German) paper which appeared on 25 April 1900 (Bib. 240).

189. The translation, by C. T. Druery, was published in 1901 with a Preface by Bateson (Introductory note to the translation of Experiments in Plant Hybridisation, by Gregor Mendel. Fournal of the Royal Horticultural Society, 26, 1-3: the translation was pp. 4-32). Bateson re-published it with modifications in his book of 1902 (Bib. 259, pp. 40-95) together with (pp. 96-103) a translation of Mendel's 1869 paper on Hieracium (hawkweed) hybrids (Mendel, G. (1870). Ueber einige aus künstlicher Befruchtung gewonnene Hieracium Bastarde. Verhandlungen des Naturforschenden Vereins in Brünn, 8, 26-31), and these remained in subsequent editions. Certain, even crucial, parts of this translation of Mendel's main paper have been criticized as being interpretive renderings (e.g. Bib. 215, p. 8 ) but it remains the standard version and was selected for re-publication in the British Medical Journal at the Mendel Centenary (British Medical fournal, I, 370-374 (1965)).

190. The Headmaster wrote to Bateson's father on 16 December 1878: ' $\ldots$ it is very doubtful whether so vague and aimless a boy will profit by University life ... I cannot think well of your son while so self-satisfied, indolent and useless'. In July 1879, while still finding Bateson 'selfsatisfied and desultory', he detects some 'vigour and character . . . and I do not despair of seeing him make a mark in the world yet' (B.B., p. 8).

191. At the height of his controversy with the ancestrians, Bateson described this episode and stated: 'Needless to say, my knowledge of mathematics is now nil' (Bateson, W. (1905). Nature, London, 71, 390). This may help to explain why Bateson never really understood the biometricians and instinctively preferred the simpler 'mathematics' of segregation and of observations based on breeding experiments.

192. Bateson showed by embryological methods that this worm might be the humblest member of the vertebrate family. Weldon, at this time Bateson's closest friend, helped him to arrange these studies and encouraged him in every way. Later, of course, this friendship dissolved in bitterness.

193. 'The annual arrival of the publisher's account was a dismal event, and then the book was put "in remainder" and dropped out' (B.B., p. 58).

194. Bib. 110 , p. 574.

195. Bateson, W. (1900). Problems of heredity as a subject for horticultural investigation. Fournal of the Royal Horticultural Society, 25, 54-61.

196. In July 1899, ten months before he first read Mendel, Bateson, when discussing the purposes of breeding, said: 'It must be recorded how many of the offspring resembled each parent, and how many showed characters intermediate between those of the parents. If the parents differ in several characters, the offspring must be examined statistically, and marshalled, as it is called, in respect of each of these characters separately' (Bateson, W. (1900). Hybridisation and cross-breeding as a method of scientific investigation. Ibid., 24, 59-66). This shows how Bateson's mind was already conditioned for the reception of Mendel's views.

197. Many 'Mendelian' terms, e.g. allelomorph, heterozygote, homozygote, were introduced by Bateson (e.g. Bib. 198). Bateson also coined the word 'genetics' for the science of the study of 'the physiology of heredity and variation', and introduced it in a review in Nature (Bateson, W. (1906). A text book of genetics. Review of Vorlesungen über Descendenz-Theorien, Etc., by J. P. Lotsy. Vol. I. Fischer, Jena, 1906. Nature, London, 74, 146-147). He had earlier suggested it in a letter to Adam Sedgwick of April 1905 (B.B., p. 69).

198. Bateson, W. and Saunders, E. R. (1902). Experimental Studies in the Physiology of Heredity. Reports of the Evolution Committee of the Royal Society. No. 1. Harrison, London.

199.,-- , Punnett, R. C., and Hurst, C. C. (1905). Ibid., No. II.

200. — - — - - (1906). Ibid., No. III.

201. —_, - - (1908). Ibid., No. IV. This Report also contains papers by Florence Durham, L. Doncaster and Dorothea Marryat. These were communicated to the Evolution Committee by Bateson.

202. Garrod, A. E. (1901). About alkaptonuria. Lancet, ii, 1484-1486. Bateson's remarks are in a report dated 17 December 1901 (Bib. 198, p. $133 \mathrm{ft}$.).

203. The lectures were later published as: Bateson, W. (1913). Problems in Genetics. Oxford University Press, London.

204. Founded for five years with an anonymous donation to celebrate the centenary of Darwin's birth (in 1809). On appointment Bateson surrendered his College Stewardship sacrificing the pension which was nearly due. In 1912 the Chair became an established one but Bateson refused the invitation to apply and Punnett was appointed as the first Arthur Balfour Professor of Genetics, a post which he held until 1940.

205. Punnett, R. C. (1952). William Bateson and Mendel's principles of heredity. Notes and Records. Royal Society of London, 9, 336-347. This was first published in the Edinburgh Review in 1926 shortly after Bateson's death. Another obituarist wrote: 'The high hopes that were entertained as soon as it became known that the Institution was placed under the charge of the foremost experimental biologist of his time, have been more than justified' (J.B.F. (1927). William Bateson, 1861-1926. Proc. Roy. Soc., B101, i-v).

206. Punnett (Punnett, R. C. (1950). Early days of genetics. 
Heredity, 4, 1-10) later explained why Bateson and himself missed associating linkage with the chromosomes: 'The answer is Boveri. We were deeply impressed by his paper "On the individuality of the chromosomes" and felt that any tampering with them by way of breakage and recombination was forbidden. For to break the chromosome would be to break the rules.'

207. E.g. Bateson's last paper (Bateson, W. (1926). Segregation : being the Joseph Leidy Memorial Lecture of the University of Pennsylvania, 1922. Fournal of Genetics, 16, 201-235).

208. This was stated as follows: '... it is nevertheless possible to express all Mendelian phenomena.... according to which allelomorphism may be represented as consisting essentially not in the presence of separate factors for the dominant and for the recessive characters, but in the presence of something constituting the dominant character which is absent from the recessive gametes. So satisfactory indeed are the results ... that the probabilities are greatly in favour of its truth.' (Bateson, W. (1907). Facts limiting the theory of heredity. Science, 26, 649-662.) In the limiting case the 'recessive' factor would be a gap in the genetic constitution otherwise occupied by the dominant. The concept was heavily attacked after the absurdity of the 'unpacking' theory had been demonstrated (Bib. 210) in the light of the occurrence of dominant mutations and the necessity of arguing, for its acceptance, that evolution was from the genetically complex to the genetically simple! The conclusive acceptance of multiple alleles in 1913 (Bib. 288), and reverse mutations, was of course to vitiate the 'presence-and-absence' hypothesis. (Swinburne, R. G. (1962). The presence-and-absence theory. Annals of Science, 18, 131-145.)

209. The arguments for its acceptance are put by Punnett (Punnett, R. C. (1912). Mendelism. 4th ed., p. 35. Macmillan, London).

210. This hypothesised the 'unpacking' of characters as evolution continues: "For instance the original "pack" might have been made in such a way that at the n-th division of the germ cells of a Sweet Pea a colour factor might be dropped, and that at the $n+n^{\prime}-$ th division the hooded variety might be given off, and so on. I see no ground whatever for holding such a view, but ... in the light of modern research it scarcely looks so absurdly improbable as before' (Bateson, W. (1910). Heredity and Variation in Modern Lights. In Darwin and Modern Science. Edited A. C. Seward, p. 101. The University Press, Cambridge). In other words, if evolution be mainly by mutation, and given that most mutations are recessive, and accepting the 'presenceand-absence' theory, then 'unpacking' implied that evolution must proceed by loss of elements from the genotype until complex organisms would be genotypically simpler than primeval organisms-a highly implausible concept since primeval organisms presumably had the fewer phenotypic characters!

211. Punnett (Bib. 206) records that he used to bring Bateson the Morning Post because 'it contained the best account of art sales, and I don't think he read much else'. Despite shortage of money when younger, Bateson left an estate sworn at $£ 25,435$.

212. Punnett, R. C. (1928). Scientific Papers of William Bateson. Edited by R. C. Punnett. 2 vols. The University Press, Cambridge.

213. B.B., passim. Also: Bateson, B. (1928). Letters from the Steppe written in the Years 1880-1887. Edited, with an introduction, by Beatrice Bateson. Methuen, London.
214. Biographical details from: B.B., passim; Punnett (Bib. 205, 206); J.B.F. (Bib. 205); Crowther (Bib. 19, pp. 248310); Dunn (Bib. 215, ch. 6); and Crew, F. A. E. (1967). Reginald Crundall Punnett, 1875-1967. Biographical Memoirs of Fellows of the Royal Society, 13, 309-326.

215. A recent general history is: Dunn, L. C. (1965). $A$ Short History of Genetics. The Development of Some of the Main Lines of Thought: 1864-1939. McGraw-Hill, London.

216. Spencer, H. (1864, 1867). Principles of Biology. 2 Vols. Williams and Norgate, London.

217. For previous theories see: Zirkle, C. (1951). The Knowledge of Heredity before 1900 . In Genetics in the 20th Century. Essays on the Progress of Genetics during its first 50 Years. Edited L. C. Dunn, pp. 35-57. Macmillan, New York.

218. Lamarck postulated four 'laws' to explain the organization of animals and formation of different organs. This was the fourth. (Lamarck, J.B.P.A. de M. (1815). Histoire Naturelle des Animaux sans Vertèbres, vol. 1, pp. 199 seq. Verdière, Paris.) The standard biography of Lamarck is: Packard, A. S. Jr. (1901). Lamarck, the Founder of Evolution: His Life and Work. Longmans, Green, New York.

219. Pfeifer, E. J. (1965). The genesis of American neoLamarckism. Isis, 56, 156-167.

220. Spencer welcomed Origin and considered that natural selection governed most evolutionary phenomena. Darwin increasingly accepted a modified Lamarckism though holding many of its main doctrines in distaste (Mandelbaum, M. (1957). The scientific background of evolutionary theory in biology. Fournal of the History of Ideas, 18, 342-361.) Subsequently Spencer moderated his views which in fact differed in physical conception as well as degree from the neo-Lamarckians, but he remained wedded to basic Lamarckism. (Bib. 219; also Fothergill, P. G. (1952). Historical Aspects of Organic Evolution, p. 164. Hollis and Carter, London.)

221. A. R. Wallace to Sir C. Lyell of 20 Feb. 1868 (Wallace, A. R. (1905). My Life: A Record of Events and Ofinions, vol. I, p. 422. Chapman and Hall, London).

222. Bib. 122 , pp. $363,367$.

223. Bib. 49, vol. 2, pp. 374, 379. Galton, F. (1871). Pangenesis. Nature, London, 4, 5-6.

224. Darwin, C. (1871). Pangenesis. Nature, London, 3 502-503.

225. Life, II, pp. 113,156 seq.

226. Galton, F. (1871). Experiments in pangenesis, by breeding from rabbits of a pure variety, into whose circulation blood taken from other varieties had previously been largely transfused. Proc. Roy. Soc., 19, 393-410.

227. Bib. 224. 'But it does not appear to me that Pangenesis has, as yet, received its death blow; though . . . its life is always in jeopardy.'

228. The development of Galton's thinking is in Life, $\mathbf{I}$, pp. 114-115, 169 seq.

229. Galton, F. (1872). On blood relationship. Proc. Roy. Soc., 20, 394-402. Galton might have formulated his theories earlier but for his high regard for Darwin (Life, II, p. 170).

230. (1875). A theory of heredity. Fournal of the Anthropological Institute of Great Britain and Ireland, $\mathbf{5}$, 329-348. Versions were also published elsewhere.

231. This last phrase was to disallow disproportionate material influence on the foetus from freely circulating gemmules.

232. Galton, as in his ancestral law, used cumbrous nontechnical terms which were not easily understood and 
accordingly his ideas were not so widely accepted as the very similar ones of Weismann. E.g. Charles Darwin to F.G. of 7 Nov. 1875 (Life, II, p. 187).

233. Weismann, A. (1883). Ueber die Vererbung. Fischer, Jena.

234. Weismann borrowed this term from Nägeli (Nägeli, C von. (1884). Mechanisch-physiologische Theorie der Abstammungslehre. Oldenburg, Munich and Leipzig) though unlike him he follows Foux and places the idioplasm in the nucleus and not the cytoplasm.

235. Weismann, A. (1887). On the significance of the polar globules. Nature, London, 36, 607-609.

236. (1904). The Evolution Theory. Translated with the author's co-operation by J.A. and Margaret $R$. Thomson. 2 vols. Arnold, London. The original work was published in 1902 . This theorized continuity of the germ-plasm led to Samuel Butler's famous remark: 'It had, I believe, been often remarked that a hen is only an egg's way of making another egg.' (Cited in Bib. 215, p. 44.)

237. The fullest contemporary critique of Weismann's theory on this point is: Romanes, G. J. (1893). An Examination of Weismannism. Longman, London.

238. de Vries, H. (1889). Intracelluläre Pangenesis. Fischer, Jena.

239. (1901). Die Mutationstheorie. Versuche und Beobachtungen über die Entstehung der Arten im Pflanzenreich. Bd. I: Die Entstehung der Arten durch Mutation. Veit, Leipzig.

240. (1900). Das Spaltungsgesetz der Bastarde (Vorläufige Mitteilung). Bericht der Deutschen botanischen Gesellschaft, 18, 83-90.

241. For review see: Hughes, A. (1959). A History of Cytology. Abelard-Schuman, London.

242. For reasons for the timing of the 'rediscovery' see: Gasking, E. B. (1959). Why was Mendel's work ignored? Fournal of the History of Ideas, 20, 60-84; and Wilkie, J. S. (1963). Some reasons for the rediscovery and appreciation of Mendel's work in the first years of the present century. British Fournal of the History of Science, 1, 5-17.

243. Boveri, Th. (1902). Ueber mehrpolige Mitosen als Mittel zur Analyse des Zellkerns. Verhandlungen der Physikalisch-medizinischen Gesellschaft zu Würzburg, 35, 67-90. For a description of Boveri's work see: Baltzer, F. (1964). Theodor Boveri. Science, 144, 809-815.

244. Sutton, W. S. (1902). On the morphology of the chromosome group of Brachystola magna. Biological Bulletin. Marine Biological Laboratory, Wood's Hole, Mass., 4, 24-39. This paper was published in December 1902 but some of the material was presented in April 1900 (Bib. 246). The present and following paper (Bib. 245), represent Sutton's own observations, while still a student, on the chromosomes of the lubber grasshopper (B. magna) in 1899 and 1900 and the influence of Bateson's Defence (Bib. 259).

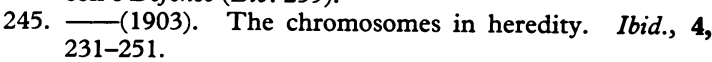

246. McKusick, V. A. (1960). Walter S. Sutton and the physical basis of Mendelism. Bulletin of the History of Medicine, 34, 487-497.

247. Johannsen, W. (1909). Elemente der Exakten Erblichkeitslehre. Fischer, Jena.

248. Fisher, R. A. (1936). Has Mendel's work been rediscovered? Annals of Science, 1, 115-137.

249. Results of the first were never published (K.P., p. 33); for those of the second see $B i b .139$.

250. K.P., p. 33 .

3-J.M.G.
251. Weldon, W. F. R. (1901). A first note of natural selection in Clausilia laminata (Montague). Biometrika, 1, 109-124.

252. (1903). Note on a race of Clausilia itala (von Martens). Ibid., 3, 299-307.

253. Weldon was an excellent linguist and, like Pearson, read and wrote German fluently (K.P., p. 15). Bateson also read German but had nothing like the mastery of the other two, and 'was always ashamed ... of his less complete mastery of German [than of French]' (B.B., p. 13).

254. K.P., p. 38 . Weldon checked everything, even the arithmetic.

255. Weldon, W. F. R. (1902). Mendel's laws of alternative inheritance in peas. Biometrika, 1, 228-253.

256. 'The studied moderation and courtesy of the [Weldon's] article' was Yule's opinion (Bib. 268). Contrast with the naked partisanship of Bateson's rejoinder written to 'defend Mendel from Professor Weldon' (Bib. 259, p. viii).

257. Mendel's results have been analysed in detail by Fisher (Bib. 248)-later reprinted with some unpublished notes by Fisher on Mendel and Mendel's paper in translation (Experiments in Plant Hybridisation, by Gregor Mendel. Edited by J. H. Bennett. Oliver and Boyd, London, 1965).

258. The experiments of Correns (Correns, C. (1900). G. Mendel's Regeln über das Verhalten der Nachkommenschaft der Rassenbastarde. Bericht der Deutschen botanischen Gesellschaft, 18, 158-168; and Ueber Bastarde zwischen Rassen von Zea Mays. Ibid., 19, 211-220) and others had established phenotype differences between homo- and heterozygote.

259. Bateson, W. (1902). Mendel's Principles of Heredity: $A$ Defence. The University Press, Cambridge. Weldon's reply to this and to $B i b .198$ was published a few months later (Bib. 264).

260. Bib. 259, p. vi.

261. 'In many well-regulated occupations there are persons known as "knockers-up" ... to rouse others from their slumber.... That part I am venturing to play this morning, and if I have knocked a trifle loud, it is because there is need' (Ibid., p. xii).

262. Ibid.: the Preface is dated March 1902. Bateson's wife (B.B., p. 74) wrote that at that time 'the outspoken hardness and clarity of the "Defence" were not idle', and refers, surely unjustly, to Weldon's article as 'an insiduous and bitter attack' on Mendelism. Yule (Bib. 268) wrote of 'the turgid and bombastic preface to "Mendel's Principles" [Bib. 259]', and of 'the grossly and gratuitously offensive reply to Professor Weldon and the almost equally offensive adulation of $\mathrm{Mr}$ Galton and Professor Pearson'.

263. Yule (Bib. 268) described Bateson's style and method as those of 'the religious revivalist [and] are ill-suited to scientific controversy. ... A writer who indulges himself in displays of this kind loses his right to be treated either as an impartial critic or as a sober speculator.'

264. Weldon, W. F. R. (1902). On the ambiguity of Mendel's categories. Biometrika, 2, 44-55. This was a firm though temperate reply. Weldon never reciprocated Bateson's acrimony.

265. Fisher (Bib. 248) put it exactly: 'It is a consequence of Darwin's doctrine that the nature of the hereditary differences between species can be elucidated by studying heredity in crosses within species.'

266. About this time Weldon reviewed (Weldon, W. F. R. (1902). Professor de Vries on the origin of species. Biometrika, 1, 365-374) the first volume of de Vries' 
Mutationstheorie (Bib. 239) in which the author distinguishes between variation proper (variations between members of a species)-which he argues can never lead to evolutionary change, and mutation-which he considers to be the mechanism of evolution of new species. The review, though adverse, is courtly and detached. One contemporary problem of Darwinian evolution, viz. that new species often appear much quicker than natural selection could allow, is considered. But the arguments on the (minor) place of Mendelism are essentially as in Bib. 255.

267. Bateson's main initial attack was on Weldon (Bib. 259) with whom he shared a common training and felt confident that he could be understood. Both were field naturalists; Weldon was not drawn into biometry by inclination but 'driven into it by the looseness he discerned in much biological logic' (K.P., p. 30). Bateson was less at ease with the applied mathematician Pearson and it was the latter's criticisms of the Mendelians which carried the greatest weight. Five days after he had read Weldon's article on Mendelism (Bib. 255), Bateson wrote to Pearson in an effort to bridge the widening gap between them (W.B. to K.P. of 13 Feb. 1902, in E.S.P., p. $232 \mathrm{ft}$.).

268. Yule, G. U. (1902). Mendel's laws and their probable relations to intra-racial heredity. New Phytologist, 1, 193-207, 222-237. Yule worked under Pearson from 1892 to 1900 but he wrote this article as Superintendent of the Department of Technology, City and Guilds of London Institute, and Newmarch Lecturer in Statistics at University College, London. (Yates, F. (1951). George Udny Yule, 1871-1951. Obituary Notices of Fellows of the Royal Society, 8, 309-323.) Yule wrote this article before the work of Sutton (Bib. 244) and Boveri (Bib. 243) and this explains his Weismann-type germ-cell element concepts and his belief that scalar traits demand blending inheritance to explain them.

269. Yule states: 'Mendel's Laws I assume to be true also [as well as the ancestral law]' (Bib. 268, p. 207). Pearson, however, considered that Yule was too uncritical of Mendelism (Pearson, K. (1902). Note on a paper by G. U. Yule. Biometrika, 1, 228-229).

270. Bib. 268, p. 207. Fisher, in his definitive synthesis (Fisher, R. A. (1918). The correlation between relatives on the supposition of Mendelian inheritance. Transactions of the Royal Society of Edinburgh, 52, 399433: republished, with a commentary by P. A. P. Moran and C. A. B. Smith, as Eugenics Laboratory Memoirs, $X L I$, C.U.P., 1966), acknowledges this pioneer paper: 'The subject had been previously opened by Udny Yule.'

271. Bib. 268, p. 236. Yule considered the general ancestral hypothesis and specifically excluded 'with regret... the special laws as to the operation of Ancestral Heredity which were formulated by Galton and Pearson... [because] the fixity of the numerical constants involved, which they imply, has not stood the test of time'. Needless to say Pearson did not let this pass without comment! (Bib. 269).

272. K.P., p. 39.

273. Pearson, K. (1903). The law of ancestral heredity. Biometrika, 2, 211-229. This paper should be read in conjunction with a later one: Pearson, K. (1911). Further remarks on the law of ancestral heredity. Biometrika, 8, 239-243. The 1903 paper was written 'not as a reply to $\mathrm{Mr}$. W. Bateson's rhetorical attack [Bib. 259] on the Law of Ancestral Heredity ... but simply to indicate ... how far it enables us to describe actually observed experience... which I am unable under any hypothesis to bring under Mendel's "Principles".' (p. $211 \mathrm{ft}$.).

274. Pearson considered that Mendelian theory could only replace ancestral theory if offspring type were completely determined by parent type. His thinking had seemingly not come around to the views adumbrated by Yule (Bib. 268) though he saw the need, if perhaps not the possibility, of a simple synthesis.

275. Pearson, K. (1902). Bib. 269, p. 229. One special point was to distinguish 'sports' from 'variations proper'. Galton had made much of the difference, one of the reasons why he had inspired both the biometric and neoMendelian schools.

276. K.P., p. 43 ; Bib. 140 , p. 53 ft. Pearson reciprocated Weldon's sense of urgency. Oddly, perhaps, Pearson nowhere mentions Yule's work in his article (Bib. 140) though he had commented on it as early as January 1903 , several months before his own paper was written. (Bib. 269).

277. Bib. 140 , p. 55 . 'Blending inheritance' was specifically denied.

278. Pearson gave theorized values of 0.33 to 0.41 for 'family size' 8 to $\infty$ rightly suggesting the latter as appropriate. On Mendel's hypothesis no restriction is imposed by family size though Pearson did not recognize this at the time (Fisher, Bib. 270, p. $401 \mathrm{ft}$.).

279. This was in the particular case where Pearson started with the AA:2Aa :aa frequencies (as the result of crossing inter se in an entire Aa population) and showed that random mating preserved these ratios in subsequent generations. He did not at that time attempt to generalize his findings for different allelic frequencies. Castle had previously grasped this idea of equilibrium (Castle, W. E. (1903). The laws of heredity of Galton and Mendel, and some laws governing race improvement by selection. Proceedings of the American Academy of Arts and Science, 39, 223-242), and Pearson's comments on this article exemplify the main sources of discord between the 'post-rediscovery' biologist and Pearson: failure to appreciate the nature of correlation and regression techniques by the former; intolerance of this fact and immoderacy in expressing it by the latter (Pearson, $\mathrm{K}$. (1904). A Mendelian's view of the law of ancestral inheritance. Biometrika, 3, 109-112).

280. Hardy, G. H. (1908). Mendelian proportions in a mixed population. Science, 28, 49-50. This was Hardy's (a Cambridge mathematician) only excursion into genetics. It was at the request of $R$. C. Punnett following some discussion on Punnett's lecture at the Royal Society of Medicine (Punnett, R. C. (1908). Mendelism in relation to disease. Proceedings of the Royal Society of Medicine, 1 (Epidemiological Section), 135-168). Punnett promptly christened it 'Hardy's law' (Bib. 206): later it became the 'Hardy-Weinberg law' (Bib. 281). Hardy dealt with the general case but only for two alleles in monohybridism. $\mathrm{He}$ is said to have written the solution on his cuff at the dinner table and because it was so elementary refused to publish it in a journal his mathematical colleagues would normally read.

281. Weinberg, W. (1908). Ueber den Nachweis der Vererbung beim Menschen. Fahresheft des Verein für vaterländische Naturkunde in Wurttemberg, 64, 369-382. Weinberg, a physician, gave his paper to the Society for Natural History in Stuttgart some six weeks before Hardy's involvement. He published other relevant coeval papers none of which became well-known until 
much later. (Stern, C. (1943). The Hardy-Weinberg law. Science, 97, 137-138; and Stern, C. (1962). Wilheim Weinberg, 1862-1937. Genetics, 47, 1-5.)

282. The argument was seemingly not always easy to follow: even Yule misconstrued some of the statements. (Pearson, K. (1907). Notice of Yule, G. U. (1906). 'On the Theory of Inheritance of Quantitatively Compound Characters on the Basis of Mendel's Laws.' In Report of Third International Conference on Genetics. Royal Horticultural Society, London. Biometrika, 5, 481-482.)

283. Quotation from Pearson, K. (1909). On the ancestral gametic correlations of a Mendelian population mating at random. Proc. Roy. Soc., B81, 225-229.

284. Pearson termed the AA homozygote a 'protozygote', the aa type an 'allozygote', and followed Bateson by terming the Aa type a 'heterozygote'.

285. Bib. 140 , p. 85.

286. 'The present investigation shows that in the theory of the pure gamete there is nothing in essential opposition to the broad features of linear regression, skew distribution, the geometric law of ancestral correlation etc., of the biometric description of inheritance in populations. But it does show that the generalised theory here dealt with is not elastic enough to account for the numerical values of the constants of heredity hitherto observed' (Ibid., p. 86).

287. Ibid., p. 54. Fundamentally, of course, no mechanism of particulate inheritance based on genes could be deduced from correlations between relatives whereas such correlations necessarily followed from 'pure gamete' theory. Pearson recognized this clearly (pp. 85-86); but this problem in logic increasingly excluded the biometric school from the forefront of many advances in genetics-which were mainly cytological and experimental.

288. Cuénot with mice (Cuénot, L. (1905). Les races pures et les combinaisons chez les souris. Archives de zoologie expérimentale et generale, 3 (4th series), notes 123-132) and Castle with rabbits (Castle, W. E. (1905). Heredity of coat characters in guinea pigs and rabbits. Publications. Carnegie Institution of Washington, 23, 1-78) first demonstrated (in 1905) the presence of more than one allele at a locus. The first clear statement of multiple alleles is probably by Sturtevant in 1913 (Sturtevant, A. H. (1913). The Himalayan rabbit case, with some considerations on multiple allelomorphs. American Naturalist, 47, 234-239). The additive effect on a character of independently segregating genes was first demonstrated experimentally by Nilsson-Ehle in Sweden, during 1908-1911 (Muntzing, A. (1951). 'Genetics and Plant Breeding'. In Genetics in the 20th Century. Edited by L. C. Dunn, pp. 473-492. Macmillan, New York).

289. Pearson attacked the theory of dominance remorselessly. Just after his paper (Bib. 140) he developed a statistical criterion, given the variability of offspring, against which to measure the adequacy of (a) the ancestral law (b) generalized 'Mendelian theory' and (c) a generalized theory of alternative inheritance, i.e. individual parental dominance. The human data tested accorded best with (a). (Pearson, K. (1904). On a criterion which may serve to test various theories of inheritance. Proc. Roy. Soc., 73, 262-280.)

290. The possibility that incomplete dominance could make Mendelianism and the ancestral law compatible was suggested as early as October 1902 (Richardson, H. (1902). Theories of heredity. Nature, London, 66, 630-631). Later (in 1909) Pearson, following Yule, developed the idea in a paper on gametic association (Bib.
283). In this Pearson concluded: 'If ( $\mathrm{Aa}$ ) were a class, or ... a group of several classes, marked by an individual somatic character-not invariably identical with the somatic character of (AA) - there would be little left of contradiction between biometric and Mendelian results as judged by populations sensibly mating at random. It is the qualified assertion of the principle of dominance by the "pure Mendelianists" which appears at present as the stumbling block.'

291. K.P., p. 44. Weldon died before publishing his 'determinantal' theory of inheritance. From extant material Pearson, in 1908, compiled an article (Bib. 141) on the hypothesis of the persistence of the chromosomes up to meiosis and the then random separation, into two moieties, of the 'unit determinants' in the paternal and maternal chromosomes. He concluded: 'if the hypothesis here dealt with were correct, it would follow that the Mendelians were merely working at one end of the scale, the biometricians somewhat further down'.

292. von Guita, G. (1898, 1900). Versuche mit Kreuzungen von verschiedenen Rassen der Hausmaus. Bericht der Naturforschenden Gesellschaft zu Freiburg i.Br., 10, 317$322 ; 11,131-138$. A review of experiments on colour inheritance is given by Bateson (Bateson, W. (1903). The present state of knowledge of colour-heredity in mice and rats. Proceedings of the Zoological Society of London, 2, 71-99), and also by Davenport (Davenport, C. B. (1900). Review of von Guita's experiments in breeding mice. Biological Bulletin. Marine Biological Laboratory, Wood's Hole, Mass., 2, 121-128).

293. K.P., p. 41.

294. Darbishire was a graduate pupil of Weldon until 1904. Punnett (Bib. 206) described him as 'a pleasant young man but rather woolly and very much under Weldon's thumb'. Another pupil, Schuster, conducted some of the breedings (Schuster, E. H. J. (1905). Results of crossing grey (house) mice with albinos. Biometrika, 4, 1-12).

295. Darbishire, A. D. (1902). Note on the results of crossing Japanese waltzing mice with European albino races. Biometrika, 2, 101-105. Pearson considered these results to be 'not quite definite enough' (K.P. to F.G. of 27 Dec. 1902, in Life, IIIA, p. 251) and pressed for a bigger series, later supplied (Bib. 296 and 306).

296. - (1903). Second report on the result of crossing Japanese waltzing mice with European albino races. Biometrika, 2, 165-171.

297. Bateson, W. (1903). Mendel's Principles of heredity in mice. Nature, London, 67, 462-463.

298. Weldon, W. F. R. Ibid., 512. Weldon seems not to allow the independent assortment of several genes controlling coat colour. Later (Bib. 300) he said that he did, and blames Bateson's presentation - and lubricityfor the contrary. And so on throughout this series of letters (Bib. 297-302).

299. Bateson, W., Ibid., 585-586. Bateson treats 'coloured coat' irrespective of its degree, as a segregating trait to reach this conclusion. He attributes the coat colour diversity in $F_{1}$ to 'heterogeneity among the gametes of one or both "pure" races'.

300. Weldon, W. F. R. Ibid., 610.

301. Bateson, W. Ibid., 68, 33-34

302. Weldon, W. F. R. Ibid., 34.

303. B.B., p. 465.

304. Weldon, W. F. R. (1903). Mr. Bateson's revisions of Mendel's theory of heredity. Biometrika, 2, 286-298. Such a treatment had been earlier promised by Weldon (Bib. 298). 
305. B.B., p. 464.

306. Darbishire, A. D. (1903). Third report on hybrids between waltzing mice and albino races. On the result of crossing Japanese waltzing mice with 'extracted' recessive albinos. Biometrika, 2, 282-285.

307. The view was briefly refuted by Bateson as an addendum to his review article (Bateson, W. (1903). Bib. 292.)

308. Darbishire, A. D. (1904). On the result of crossing Japanese waltzing with albino mice. Biometrika, 3, 151.

309. The mice breedings were continued by Weldon and Sherlock and by Mrs. Weldon after her husband's death (K.P. to F.G. of 29 May 1907 and 24 Dec. 1908, in Life, IIIB, pp. 315, 360). They were to have been fully written up (K.P., p. 41) and a first paper, on sex-ratio and litter size, was prepared (Pearson, K. (1907). On heredity in mice from the records of the late W. F. R. Weldon. Part I: On the inheritance of the sex-ratio and the size of litter. Biometrika, 5, 436-450) but subsequently only a record of matings was published (Biometrika, 11, Appendix pp. 1-60 (1915-1917)). (See also $B i b$. 1, items 358 and 377.) Punnett (Bib. 206), a partisan Mendelian, discusses a 'fallacy' in Darbishire's treatment which prevents the otherwise unequivocal acceptance of Mendelism, and Bateson dismisses Darbishire's evidence against 'gametic purity' as unproven (Bib. 199, p. 131). Pearson did the opposite: he criticized Darbishire for accepting Mendelism too easily! (Bib. 312). Darbishire, after leaving Oxford, switched to experiments with peas (Darbishire, A. D. (1909). An experimental estimation of the theory of ancestral contributions in heredity. Proc. Roy. Soc., B81, 61-79), but his conclusions again did not satisfy Pearson (Pearson, K. (1909). The theory of ancestral contributions in heredity. Ibid., 219-224). Darbishire, in trying to be objective and circumspect, pleased no-one. (See also Bib. 312.)

310. Bateson, W. (1904). Presidential address to the zoological section, British Association. Reports of the British Association for the Advancement of Science, pp. 574-589.

311. Friday, 19 August 1904. Reports of papers in Ibid., pp. 590-593 (1904), and Nature, London, 70, 538-539.

312. Darbishire's neutrality was resented by Pearson who challenged his results ostensibly for inconsistency in description but really for too easily accepting Mendelism for the waltzing trait. This was in a characteristic letter to Nature (Pearson, K. (1904). The Mendelian quarter. Nature, London, 70, 529-530) in which Weldon is described as 'a recessive biometer' and Bateson 'a dominant anaesthetist'. See also Bib. 309. Bateson's school also bred mice from 1903 but the results were not presented until 1908 (Durham, F. M. (1908). A preliminary account of the inheritance of coat-colour in mice. In Bib. 201, pp. 41-53).

313. Bib. 206. The contemporary sources in Bib. 311 and Punnett's later account differ only in inessentials.

314. Nature, London, 70, 539 (1904).

315. K.P., p. 44.

316. K.P. to F.G. of 4 July 1909 (Life, IIIA, pp. 387-388). Also K.P., p. 44. Pearson considered himself a defender in the controversies and not the aggressor: 'Our policy is to work steadily away building up for the future. So long as the Mendelians do not attack us we will leave them alone' (K.P. to Mrs. Weldon in 1907, in Pearson, E. S., Bib. 139, p. 174).

317. The style of the protagonists' exchanges can be seen in microcosm in their correspondence of 1904 (Biometrika, 3, 107-109, 471-472) and 1905 (Ibid., 4, 231-232) on Arcoleo's 1871 article on albinism in Sicily. The pages of Biometrika were not completely closed to Bateson!

318. See Bib. 76, 91, 92 and 273. Also: Blanchard, N. (1902). On the inheritance in coat-colour of thoroughbred horses (grandsire and grandchildren). Biometrika, 1, 361364: (1903). Ditto (grandam and grandchildren). Ibid., 2, 229-234; and Lee, A. (1903). On inheritance (greatgrandparents and great-great-grandparents and offspring) in thoroughbred racehorses. Ibid., 2, 234-236.

319. Hurst, C. C. (1906). On the inheritance of coat colour in horses. Proc. Roy. Soc., B77, 388-394.

320. W.R.F.W. to K.P. of November 1905 (K.P., p. 47)

321. Weldon, W. F. R. (1906). Note on the offspring of thoroughbred chestnut mares. Proc. Roy. Soc., B77, 394-398.

322. Facts from Bib. 206 and K.P., 47-48.

323. Weldon's thoroughness is shown by the fact that at his death he was extracting extensive material from The General Stud Book on the basis of 'a whole population, not with a small random sample' (K.P., p. 48). His results were incomplete at his death and were never published.

324. F.G. to K.P. of 16 April 1906 (Life, IIIA, p. 280).

325. W.B. to B.B. of April 1906, in B.B., p. 103 . (See also Bib. 108.)

326. F.G. to 'Milly' of 21 April 1906 (Life, IIIB, p. 569).

327. K.P. to Mrs W.F.R.W. of April 1906 (Pearson, E. S., Bib. 139, p. 163).

328. K.P. to F.G. of June 1906 (Life, IIIA, p. 285).

329. K.P. to F.G. of 29 April 1906 (Ibid., p. 282).

330. At the Darwin-Wallace Celebration of the Linnean Society on 1st July 1908, Bateson was placed beside Pearson. Pearson wrote: 'I awaited his coming with expectation. ... But Bateson refused [my greeting] and sat sideways on his chair, with his back to me, the whole of the medal distribution....' (Life, IIIA, p. 340). When Pearson was invited to contribute a chapter to the Cambridge Darwin Centenary volume (Darwin and Modern Science, Bib. 210) Bateson, a member of the organizing committee, threatened to withdraw all his support. Pearson did not contribute (Life, IIIA, p. 369: see also pp. 288, 314, 388).

331. It is said that when Fisher submitted his classic synthesis (Bib. 270) to the Royal Society it was refereed by Pearson and Bateson. They were in unusual agreement; they both recommended rejection! The paper was subsequently published by the Royal Society of Edinburgh (Leading Article (1965). The centenary of Mendel's discovery. British Medical fournal, i, 327-328.)

332. One of the series of publications from the Biometric Laboratory (written mainly by Pearson) and included under the Draper's Company Research Memoirs is entitled Questions of the Day and of the Fray. They dealt critically and often polemically, with controversial social and scientific issues, especially with answering criticisms of the work of Pearson and his staff. This sense of intellectual combat, the 'fray', was Pearson's main emotional outlet after he more or less dropped his earlier literary, philosophic and political writing.

333. E.S.P., p. 241.

334. Some of Pearson's most laborious work in genetics still lay ahead of him in 1906, but much was in defence of his existing ideas rather than innovation of new ones. (Bib. 1.) 